\title{
Uncommon Clinical Manifestations of Cysticercosis
}

\author{
Humberto Foyaca Sibat and Lourdes de Fátima Ibañez Valdés
}

Additional information is available at the end of the chapter

http://dx.doi.org/10.5772/53078

\section{Introduction}

Cysticercosis, a parasitic infection caused by the larval form of the pork tapeworm, Taenia solium, is increasingly recognized as a cause of epilepsy, headache, and neurological signs when it is located in the brain, optic nerve or spinal cord, known as neurocysticercosis (NCC). A high prevalence of cysticercosis/taeniosis has been reported from the developing countries because of the coexistence of poor sanitary conditions and domestic pig raising without veterinary control or surveillance systems. It occurs mainly in Eastern and Southern Africa, China, India, Mexico, Central America, Chile, Ecuador, Colombia, Venezuela, Peru, Brazil, Papua New Guinea, and non-Islamic South East Asia where human faces reach pigs and pork is eaten raw or undercooked.

An infection which leads to extra-intestinal disease (including NCC) usually occurs as a result of eating food or drinking water contaminated by human feces containing T. solium eggs. It is a preventable and potentially eradicable neurological disease which primarily affects people living in the developing world. The disease is endemic in Central and South America, Asia and Africa. There is a variable time interval between point of infection and the onset of symptoms: ranging from 1-30 years.

Seizures are widely reported to be the most common symptom, occurring in $70-90 \%$ of patients. Most patients respond to praziquantel if cystic lesions are located in the parenchyma tissue and albendazole when parasites are located in the ventricular system and subarachnoid space [1-16]. Seizure disorder is the most frequent clinical manifestation of the NCC observed in $50 \%$ to $80 \%$ of cases, in children and adults presenting intraparenchymal cystic lesions. [13-44]

Each day the cysticercosis is more and better known in the developed world or in developing countries, the immune diagnostic techniques are more reliable and neuroimaging studies are more accurate. The greatest success in the diagnosis of the disease 
control passes at the achievements attained by the agricultural sector, without which it is not possible try to sustain successful results. The knowledge that we have on the porcine cysticercosis today are much more certain and deep. In the epidemiological aspects, the African continent goes up to the head because it is the only basic information that has been made safe for almost all their countries, as can be seen in the chapter: "Agricultural Impact of Porcine Cyisticercosis in Africa: A Review" in this book written by Helena A Ngowi et al. This study included information from 54 African countries that were fully recognized by the United Nations as of 2012. The total population of pigs estimated in the study area in 2010 amounted $29,606,438$. This was approximately $3.1 \%$ of the world pig population estimate (N $=965,855,414$ ) of 2010 . Out of the Africa regional pig population, approximately $0.2 \%$ was reared in the northern countries, while $6.1 \%, 43.3 \%, 16,4 \%$, and $34.0 \%$ were reared in the southern, western, central, and eastern Africa, respectively. Overall, 19 (35.2\%) of the 54 study countries reported prevalence of cysticercosis in pigs. While no data were available in the northern region, the remaining regions provided prevalence data, with more reporting frequency observed in the Eastern followed by Central Africa.

All these previous arguments together have favored the growing number of diagnosed uncommon presentations of cysticercosis that before passing unnoticed.

For purely didactic reasons we are going to aggregate all the uncommon forms of cysticercosis in accordance with the following classification:

- Uncommon cysticercosis in the head and neck

- Uncommon cysticercosis in the trunk

- Uncommon cysticercosis in the abdomen

- Uncommon cysticercosis in the limbs

\section{Uncommon cysticercosis in the head and neck}

\subsection{Uncommon clinical presentations neurocysticercosis (UNCC)}

Pseudoseizures and epilepsy in patients presenting neurocysticercosis

In our experience, the South African patients with NCC and fictitious attacks (pseudoseizures) are more often in young women with a history of violations and/or sexual abuse and their attacks are usually characterized by absence of post ictal signs, irregular and asymmetrical stereotyped movements, and often accompanied by shouts or sounds in the middle of the "attack" that usually last for more than three minutes if the patients are not alone. We found that these manifestations contribute to characterize clinically patients with pseudo-crisis. These conclusions were the result of a study conducted some years ago. [4]

Refractory epilepsy in HIVIAIDS patients presenting NCC

At the present moment, more than 40 million people are living with HIV and more than 50 million people have neurocysticercosis (NCC) worldwide. About $5 \%$ of patients with HIV and most of the patients with NCC develop recurrent epileptic seizures. Although this comorbidity has not been reported as an additional public health problem, NCC and the HIV/AIDS infections are very common in the former Transkei (South Africa) and both cause 
recurrent epileptic seizures frequently. [3,5] Usually patients with NCC have partial seizures with or without secondary generalization. The epileptogenesis in patients with NCC can be attributed to several factors, such as: inflammation, gliosis and its frequent location in the frontal and temporal lobes. [47] While the basis for seizure production in HIV-positive patients include HIV itself, mass lesions, meningitis, encephalitis, ischemia, metabolic derangement, and drugs [48] In both conditions we recognize patients as epileptic when they present recurrent unprovoked epileptic seizures associated to a chronic brain disorder. [14]

We consider refractory epilepsy when seizures are so frequent that limit the patient's ability to live fully in line with their wishes and their physical and mental capabilities or when the antiepileptic drug (AED) does not control the crisis or their side effects are limited to a person's normal development. [6] Other authors have the same criteria. [49] Recently, The International League against Epilepsy has defined the patients with epilepsy resistant to drugs when there are no controls over the attacks with a combination of two AED well tolerated, and managed properly elected. BY understanding how the lack of control when the patients continue to have attacks with an interval of not less than one third of which presented before starting the antiepiileptic treatment [14]

Although this clinical presentation is not uncommon in our setting it may be very uncommon in other countries. Nevertheless, there is a novel presentation of motor partial simple seizures localized in the lower part of the hemiface in females at the stage IV of HIV/AIDS and CD4 below $100 \times 10^{6}$. This type of seizures becomes secondarily generalized a few days or weeks of the beginning and are still uncommon in our region. At the present moment the mortality rate for these patients is $100 \%$.

Managing seizures in HIV-positive patients present specific challenges, including the identification and treatment of the underlying cause, recognition that seizure production may be multifactorial, selection of the appropriate AED, and consideration of the effects of co-administered highly active antiretroviral therapy (HAART). Unfortunately, there has been little systematic study in these areas. The available information is confined to case reports, retrospective analyses, and small studies. [48] The cause of the seizures will depend on the stage of HIV infection. Since the causes are many and there may be more than one mechanism for seizure production, a meticulous clinical, laboratory, and neuroimaging survey must be undertaken. The older AEDs, phenobarbital, phenytoin, carbamazepine, and valproic acid are still widely used. [48] In our experience Valproic acid is the AED of choice for HIV/AIDS patients with epilepsy due to NCC and we did not find increased viral load in our series of these patients on HAART.

Finally we like to highlight that apart from NCC/HIV/AIDS sometimes other causes should be investigated for a better control of the seizures. [9]

Dementia is another uncommon presentation of NCC [50] and its prognosis is better if there is not an associated HIH/AIDS.

\section{Massive neurocysticercosis}

Massive brain infection with viable cysticerci, undetectable inflammatory reaction on CNS imaging, and an unexpectedly high (82\%) prevalence of tapeworm infection represents a 
particular presentation of neurocysticercosis is different from the previously described syndromes of cysticercotic encephalitis and disseminated systemic cysticercosis according with Garcia et al. [51] In our series we did not find remarkable differences excepting a fatal prognosis when more than one thousand of cystic lesions are present $[14,16]$ but without doubt it is another uncommon clinical presentation of NCC. (Figure 1)

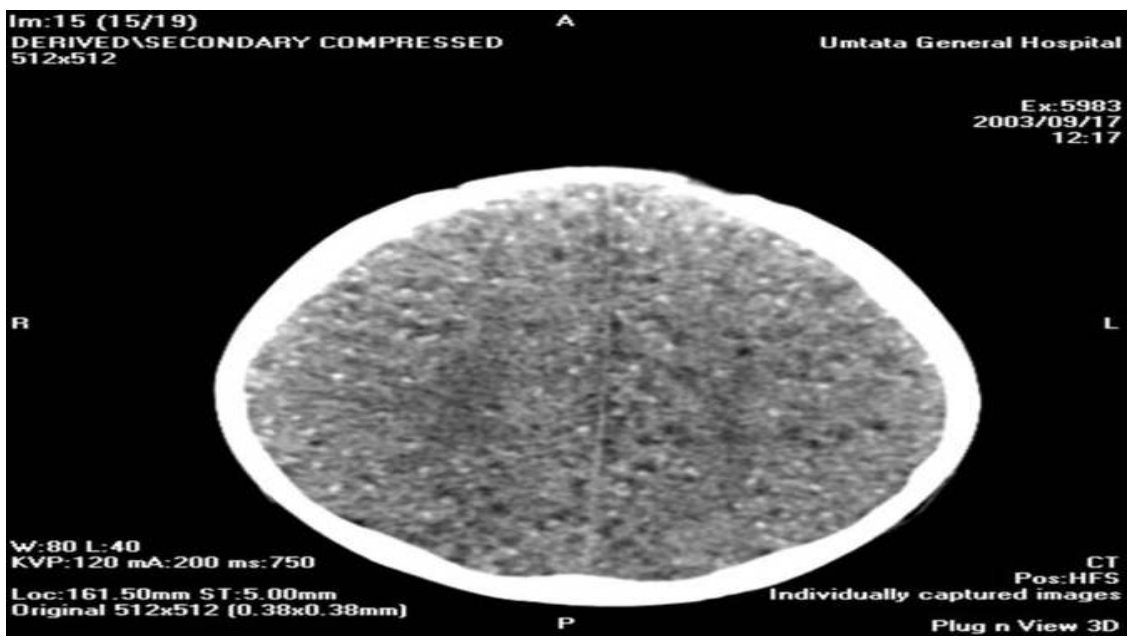

Figure 1. CT scan of the brain showing massive neurocysticercosis (more that 100 cysts)

\section{Giant intraparenchymal/Giant subarachnoid neurocysticercosis}

Parenchymal cysts usually involve the gray white matter junction, however giant cyst is usually located at the Sylvia fissure or deeper in the cerebral lobe.

Giant NCC is a rare condition defined by various authors as measuring more than five $\mathrm{cm}$ in its largest dimension [52] usually associated with intracranial hypertension but giant cysts may not always be associated with elevated intracranial pressure, probably due to slow growing of the cyst.

Almost all reported patients presenting intraparenchymal giant cyst had similar clinical manifestations at the beginning characterized by headache, altered mental status, hemiparesis mainly on the right side [9, 53-62] or uncontrolled epilepsy. [63] Between 1990 and 2006, only five patients have been reported in South Africa. All had associated epilepsy, one patient also presented visual hallucinations, dysnomia in blue and red, dyslexia and palinopsia, and the cyst $(106 \mathrm{~mm})$ was located in the left occipital lobe. [9] (See figure 2)

All patients were treated with a 31-day course of praziquantel $50 \mathrm{mg} / \mathrm{kg}$ daily. Two patients had corticosteroids administered simultaneously. All five patients had anticonvulsant cover. In all cases there was rapid and complete resolution of the cysts. In three patients this occurred within 30 days. The computed tomographic features of giant cysticercal cysts in our series were: thin walled cystic lesions containing clear fluid, localized thickening of the wall with an eccentric scale in three patients, the absence of pericyst edema, and the 
presence of associated smaller and more typical cysticercal larval forms. Identification of a scolex in a cystic lesion with CSF intensity plays a key role in the diagnosis of NCC and the presence of internal septations is an atypical feature. [61]

Giant cysticercal cysts resolve remarkably rapidly on medical therapy. A therapeutic trial of praziquantel can, in suspected giant cysticercal cysts, obviate the need for exploratory craniotomy. $[9,56]$ Other authors [60] suggest repeating anthelmintic treatment to provide good response, when it is necessary, and we fully agree on that. However, surgical treatment may be required when it is associated with elevated intracranial pressure, [62] mainly if the pre-operatory diagnosis is not clear enough.
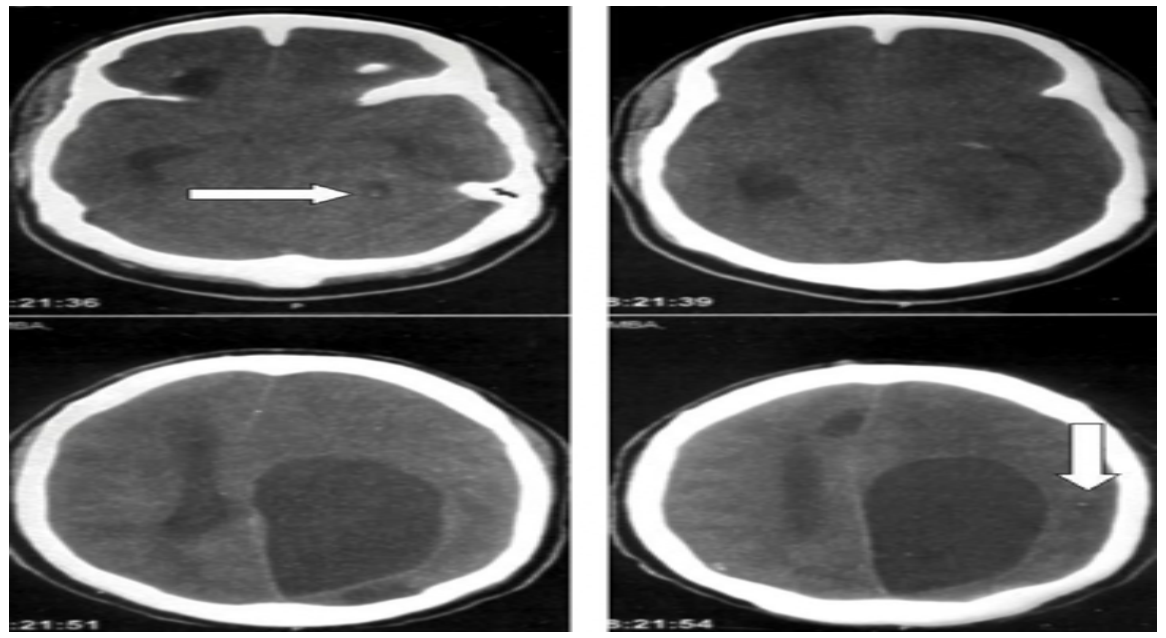

Figure 2. In upper right and lower left white arrow show identification of active viable cyst in vesicular stage with an eccentric scolex. Giant cyst measuring $106 \mathrm{~mm}$ on the left occipital lobe is seen.

\section{Neurocysticercosis in the posterior cranial fossa}

The posterior cranial fossa is part of the intracranial cavity, located between the foramen magnum and tentorium cerebelli. It contains the brainstem and cerebellum. This is the most inferior of the fossa. It houses the cerebellum, medulla and pons. Anteriorly it extends to the apex of the petrous temporal. Posteriorly it is enclosed by the occipital bone. Laterally portions of the squamous temporal and mastoid part of the temporal bone from its walls.

In the posterior fossa, NCC can involve the fourth ventricle, cerebellopontine angle cistern, cisterna magna and rarely, the cerebellum $[64,65]$.Cysticercosis affecting one of the abovementioned anatomical structures are grouped under the name of NCC of the posterior fossa (PFNCC).

One of the first articles about clinical manifestations was done by Bickerstaff et al., in 1956 [66] and about clinical and surgical management by Kla in 1964. [67] Other modalities of management including the diagnostic importance of laboratory and serological analysis of blood and cerebro-spinal fluid in cysticercosis of the posterior cranial fossa and description 
of the pseudotumoral form of Cysticercus cellulose to be remembered when one attempts to characterize the type of neoplasms of the posterior fossa as detected by brain scan in the infantile population were reported from 1971 and 1978. [68-71]

Anecdotal clinical presentations in patients with posterior fossa involvement may include signs of bilateral fourth nerve palsy, facial myokymia, upbeat nystagmus, periodic alternating nystagmus, and rhythmic oculopalatal myoclonus. [72] In patients presenting huge cystic lesions due to PFNCC then intermittent severe headache, epilepsy, and signs of raised intracranial pressure, cerebellar signs and cranial nerves signs can be seen. [63,73] Studies post-mortem have confirmed this correlation between signs of increased intracranial pressure, localizing cerebellar signs and even hearing loss in patients presenting PFNCC in the cerebellopontine cistern and obstructive hydrocephalus. [74,75]

Sang-Wook et al. [76] reported a case presenting headache, dizziness, drowsiness and ataxic gait. The magnetic resonance imaging showed hydrocephalus and an ill-defined, multicystic cerebellar mass with hypersignal on T2-weighted images, hyposignal on T1-weighted images and rim enhancement after gadolinium injection (the differential diagnoses of include abscess, tuberculosis, metastasis and other parasitic diseases). The patient underwent endoscopic third ventriculostomy and the cyst resection was done through a craniotomy. In surgical field, cysts were conglomerated in a dense collagen capsule that were severely adherent to surrounding cerebellar tissue, and transparent cysts contained white, milky fluid. Histological findings confirmed the diagnosis of cysticercosis. These authors concluded that racemose cysticercosis is rare in the cerebellar hemisphere but neurocysticercosis should be taken into consideration as a differential diagnosis of multiple cystic lesions in the cerebellum and we agree on that. As has been mentioned, $\mathrm{T}$ solium cysticercosis spread through the bloodstream and it may locate almost anywhere in the CNS, most frequently involves the cerebral hemispheres and sometimes ventricles, basal cisterns, subarachnoid space, and spinal cord. Cerebellar cysticercosis has been rarely reported [77-78]. Anecdotal presentations include multiple cranial nerve involvement (V, VI, VII, VIII) and cerebellar signs resembling anterior inferior cerebellar artery (AICA) syndrome. [79]

Other uncommon clinical locations of NCC (UNCC) are: intraventricular (IV), intra-spinal (IS), subarachnoid (SA) and others that we will explain below.

\subsubsection{Neurocysticercosis intraventricular (IVNCC)}

The ventricular system is a set of structures containing cerebro-spinal fluid in the brain. It is continuous with the central canal of the spinal cord. The ventricles are filled with cerebrospinal fluid (CSF) which bathes and cushions the brain and spinal cord within their bony confines. Cerebro-spinal fluid is produced by modifying ependymal cells of the choroid plexus found in all components of the ventricular system except for the cerebral aqueduct and the posterior and anterior horns of the lateral ventricles. CSF flows from the lateral ventricles via the foramina of Monro into the third ventricle, and then the fourth ventricle via the cerebral aqueduct in the brainstem. From there it can pass into the central canal of 
the spinal cord or into the cisterns of the subarachnoid space via three small foramina: the central foramen of Magendie and the two lateral foramina of Luschka. The fluid then flows around the superior sagittal sinus to be reabsorbed via the arachnoid villi into the venous system. CSF within the spinal cord can flow all the way down to the lumbar cistern at the end of the cord around the cauda equina where lumbar punctures are performed.

The aqueduct between the third and fourth ventricles is very small, as are the foramina, which means that they can be easily blocked, causing high pressure in the lateral ventricles. This is a common cause of hydrocephalus (known colloquially as "water on the brain"), which is an extremely serious condition due to both the damage caused by the pressure as well as the nature of whatever caused the block (e.g. a tumour, cyst or inflammatory swelling). The cavities of the cerebral hemispheres are called lateral ventricles, or 1st \& 2 nd ventricles. These two ventricles open commonly into the $3 \mathrm{rd}$ ventricle by a common opening called the foramen of Monro.

The presence of $\mathrm{T}$ solium in the ventricular system may be seen in a 7-30\% of patients with NCC [45] and although it has been reported less frequently (6\%) by other authors [46] everything seems to indicate that its frequency is much greater than had been thought previously. [45] Of all forms of presentation of the NCC, the IVNCC is sometimes associated with a fatal prognosis. The diagnosis of certainty is achieved by methods of neuroimaging, particularly the nuclear magnetic resonance imaging (MRI), which is also indispensable as prior checking to surgery, the choice of treatment and assessment of the response to the same. [80-82]

Some reports related to the clinical characteristics and the management of this entity confirm their increasing frequency in countries such as the Unite States of America. [83, 84] In 1906, Ludwig Bruns described a phenomenon characterized by sudden headache associated with acute vestibular syndrome, triggered by sudden movements of the head, or, at times, it could have a disastrous outcome, by leading to coma and even death. [85] A form of presentation of the NCCIv may be syndrome Bruns characterized by episodes of loss of consciousness to head movements and hydrocephalus due to a cyst in the IV ventricle their movement obstructs the exit of CSF through the holes of Luchka and Magendie, involuntary movements or intracranial hypertension. [86] Other clinical manifestations of the NCCIv have been reported according to the location of the cysticerci in the ventricular system [87] or when passing through the same. [88] The NCCIv of the lateral ventricles has not been reported that constitutes a diagnostic or therapeutic problem however the NCCIV of the III and IV ventricles constitute a major challenge to resolve. [80,89] The treatment of forms Iv is geared toward case by case, according to the pathogenic substrate. The first thing to define is the presence or risk of acute hydrocephalus, and, therefore, the option of a ventriculostomy emergency or making a ventriculoperitoneal shunt (DVP), with or without fenestration of the septum, according to the location of the Ct. To take the decision to remove the cysts must be taken into account: the number, location stage of cysticercus, general clinical conditions of the patient, abilities, and experience of the surgical team to perform open or endoscopic neurosurgical approach. [90, 91] Also add to the list other criteria such as: the mass effect, the ventricular obstruction, the dysfunction of the valve and 
the diagnostic doubt. [90] Some authors have argued that the confirmation of contrast in the wall cysticercus by MRI is a sign of a poor prognosis independent of the applied surgical treatment, as it translates the possibility of a process of ependimitis that will tend to chronicity with obstruction or entrapment, independent of the presence of the Ct. [90] The treatment of forms Iv includes not only surgical options, but also with anti-parasitic treatment (APT), corticosteroids [87, 90-93] and VPS when necessary. It is important to mention that the APT of the NCCIv should be indicated if there is a possibility to make an emergency-relief through a VPS in the case of acute obstruction. Variations in the number, volume and involution of the $\mathrm{Ct}$, the secondary reactions, the eventual hydrocephalus, as well as the low number of patients who have this form of presentation, make it unlikely to carried out randomized clinical trials with an acceptable confidence. [94] On the other hand, Ramirez-Ceballos and Marquez [97] argue that the NCCIv requires an individualized treatment, medical, surgical, or a combination of both and in their experience Iv neuroendoscopic has provided a good surgical approach allowing to explore properly the ventricular cavities with either the rigid or flexible endoscope. According to these authors, this treatment improves the prognosis and clinical course of patients, since in most of them it avoids the placement of derivatives systems and in those cases that require, decreases the risk of re-surgical interventions. In this regards, we did not find articles related to the NCCIv and infection by HIV/AIDS, its clinical features and treatment options therefore it will be another aspect to be discussed below from our results.

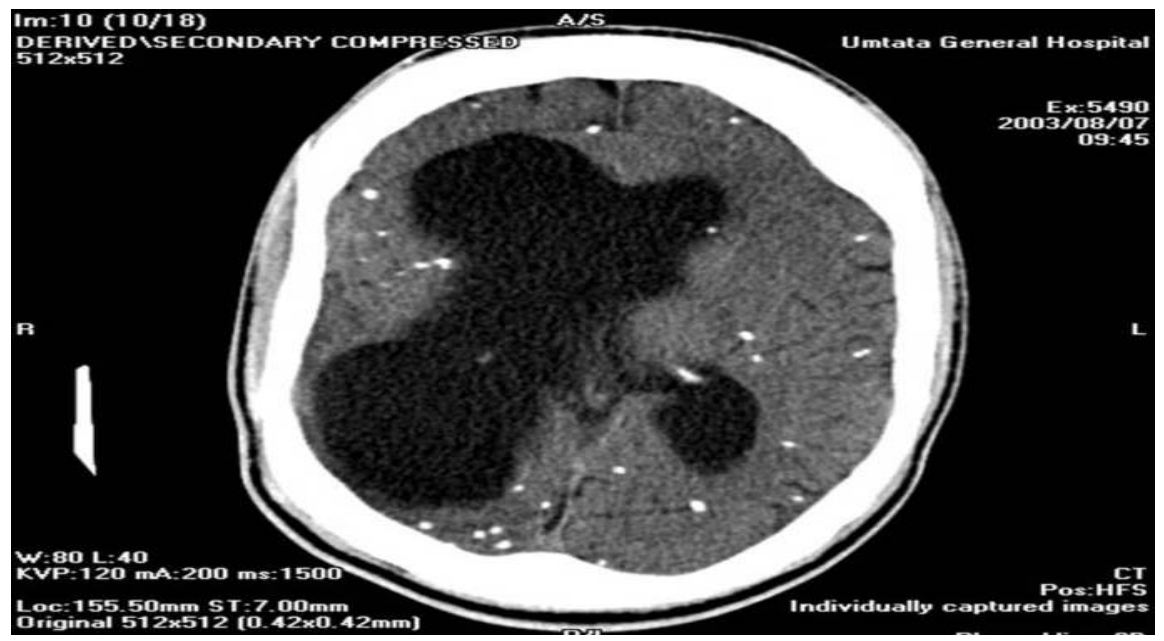

Figure 3. CT scan of the brain showing asymmetrical hydrocephalus due to intraventricular neurocysticercosis blocking foramen of Monro on the right side and calcified NCC.

Patients presenting intraventricular NCC (IvNCC) can have a different clinical presentation if they are HIV positive [2,3], although they have in common that the diagnosis must be confirmed by MRI as other have also pointed outr. [80, 97, 98] Should be emphasized that in HIV patients must be ruled out the presence an associated chronic meningitis by favoring the ventricular dilatation, (See figure 3) and in which case the serial lumbar punctures 
should be assessed carefully. The ABZ is the drug of choice, [2,3] if removal of the Ct by endoscopic is not possible. $[15,16,90,91]$

\section{Fourth ventricular neurocysticercosis (FVNCC)}

Despite fourth ventricle is located in the posterior fossa, we decided to place apart here for didactic purposes, and because the fourth ventricle is the most frequent site of intraventricular infestation, a location that carries a higher risk of raise intracranial pressure due to cerebro-spinal fluid (CSF) blockage. We will comment a little bit more about this particular location of $\mathrm{T}$ solium cysticercosis.

The fourth ventricle is one of the four connected fluid-filled cavities within the human brain. These cavities, known collectively as the ventricular system, consist of the left and right lateral ventricles, the third ventricle, and the fourth ventricle. The fourth ventricle extends from the cerebral aqueduct (aqueduct of Sylvius) to the obex, and is filled with CSF. The fourth ventricle has a characteristic diamond shape in cross-sections of the human brain. It is located within the pons or in the upper part of the medulla. CSF entering the fourth ventricle through the cerebral aqueduct can exit to the subarachnoid space of the spinal cord through two lateral foramina of Luschka and a single, midline foramen of Magendie.

Clinical and imagenological aspects on FVNCC has been described in the medical literature [99- 108] and can be sumarized as follow: Symptoms and sings of intracraneal hypertension due to obstructive hydrocephalus [99,100-107] , blurred vision, loss of consciousness, [100] sudden death, [108] reversible parkinsonism following ventriculoperitoneal shunt, [109] Bruns syndrome, [110] positional vomiting [111] and comatose state [112]

From the point of view of imagenology, the magnetic resonance imaging (MRI) is the investigation of choice which can also show: cerebrospinal fluid (CSF) signal intensity (on all pulse sequences), intra fourth ventricular cyst with scolex, and wall enhancement. On T1weighted and Fluid Attenuation Inversion Recovery images (FAIR), the cyst wall and scolex which are not seen in other routine sequences, and the CSF flow study can show the intraluminal nature of the cyst [113] and the even imagenological appearance of multicystic tumor. [114]

Most studies have been addressed to review the therapeutic approaches of IVNCC, as can be seen in our review. [99,110,115-127] and has been well established that available treatment options are: medical, external cerebro-spinal fluid diversion, microsurgical, or endoscopic removal alone or in combination. [122] Summarizing the reports in the medical literature we can conclude that the best choices for treatment of IVNCC are:

1. Albendazol (15 mg/kg/day for 2 weeks): A regimen of albendazole is the treatment of choice for IVNCC even after surgical procedures [122], although praziquantel may also be useful. [117]

2. Praziquantel $(100 \mathrm{mg} / \mathrm{kg} /$ day for 2 weeks): Rapid regression of a large cyst of the fourth ventricle after oral praziquantel, avoiding the need for surgery has been reported. [116] 
3. Direct surgical excision of the parasite after a shunt procedure is performed, [115] but the complication rate is high due to obstruction or material infection, which may justify other procedures such s endoscopic third ventriculostomy, [122] as you can read below. Resection of the fourth ventricle lesion through a sub occipital approach allowed for restoration of normal cerebro-spinal fluid (CSF) flow and relief of midbrain compression. [112]

4. If pericystic enhancement is present on MRI, shunt surgery should be performed, and craniotomy reserved for treatment of those patients with symptomatic lesions secondary to mass effect.[119]

5. Endoscopy approach: Neuroendoscopy provides a safe and effective management modality for the treatment of a variety of intracranial disorders, either temporal or nontumoral, congenital, developmental, and degenerative, and its knowledge, indications, and limits are fundamental for the armamentarium of the modern neurosurgeon. [126] In patients presenting symptomatic obstructive hydrocephalus, aqueductal and foramen of Monro dilatations, endoscopic neurosurgery is a minimally invasive technique enabling removal of intraventricular cyticercal cysts from all locations, avoiding major craniotomies/posterior fossa explorations and shunts. The flexible fiberoptic scope is used for excising cysts in the fourth ventricle, through a transaqueductal route and patients should be treated with albendazole in the postoperative period. [118, 120,122] Endoscopic third ventriculostomy for patients with ventricular outlet obstruction and a prior history of FVNCC has been reported as a successful management and no patient has required subsequent surgery. [121, 122] Endoscopic transaqueductal removal of fourth ventricular neurocysticercosis with an angiographic catheter has been used and there are good experiences from two series of 10 and 21 patients with IVNCC with obstructive hydrocephalus that underwent endoscopic removal along with endoscopic third ventriculostomy through a frontal precoronal burr hole. The author concluded that a 30-degree rigid telescope provide excellent image quality, with the ability to address intra-FVNCC through the dilated aqueduct with a curved-tip catheter without significant operative or postoperative complications. They concluded that neuro-endoscopic surgery is an effective treatment modality for patients with intraventricular NCC. It effectively restores CSF flow and is capable of removing cysts completely or partially from accessible locations causing mass effect. Partial removal or rupture of the cyst does not affect the clinical outcome of the patients. [123, 124] Other series of patients (n-13) presenting FVNCC with complete excised of cyst by using a transventricular, transaqueductal "scope-in-scope" endoscopic technique was reported and their author also concluded that endoscopic fourth ventricular cysticercal cyst excision along with internal cerebrospinal fluid diversion via endoscopic third ventriculostomy is an effective alternative to open microneurosurgical procedures and avoids shunt placement and its related complications [125] such as: Parkinsonism with evidence of midbrain dysfunction due to aqueductal stenosis after placement of ventriculoperitoneal shunt. [110] 


\subsubsection{Subarachnoid NCC (SANCC)}

In the central nervous system, the subarachnoid space (SAE) is the interval between the arachnoid membrane and pia mater. It is occupied by spongy tissue consisting of trabeculae (delicate connective tissue filaments that extend from the arachnoid mater and blend into the pia mater) and intercommunicating channels in which the CSF is contained.

This cavity is small on the surface of the hemispheres of the brain. On the summit of each gyrus the pia mater and the arachnoid are in close contact, but in the sulci between the gyri, triangular spaces are left, in which the subarachnoid trabecular tissue is found. Whilst the pia mater closely follows the surface of the brain and dips into the sulci, the arachnoid bridges across them from gyrus to gyrus.

At certain parts of the base of the brain, the arachnoid is separated from the pia mater by wide intervals, which communicate freely with each other and are named subarachnoid cisternæ; in these the subarachnoid tissue is less abundant. The subarachnoid space is the location of the interface between the vascular tissue and the cerebro-spinal fluid and is active in the blood brain barrier.

The arachnoid mater continues down the spinal cord, and the subarachnoid layer with it. It serves a similar function in the spinal cord as it does in the brain.

Despite SANCC is an uncommon location compare with intraparenchymal NCC, the commonest location in the subarachnoid space is over the cerebral hemispheres.

In 2004, Wallin and col. [128] reported the prevalence of SANCC in 2\% while other authors reported a higher prevalence (3.5\%) in patients with SANCC with visual and hormonal disturbances secondary to a direct compression of the pituitary stalk and the optic nerve, $[129,130]$ in some studies it was not clear whether refers to the frequency of complications by compression of the optic nerve and the pituitary stalk within the group of patients with SANCC or within a group of patients with NCC in general. As in the above situations, the treatment of choice for the SANCC is individual. [94] There are numerous reports of cases and a series of cases treated with cesticidas and corticosteroids to repetition, but not compared with a control group, to confirm this hypothesis with the additional benefit of reducing the size of the cysts or of the inflammatory leptomeningeal process. [131,132] Despite the lack of evidence which originated in randomized clinical trials, there is consensus for this option [133] and other authors combine prolonged treatments (sometimes for several months) with cesticidas and corticosteroids. [134] According to some authors the reason why the clinical manifestations of ischemia with or without infarction, due to cerebral vasculitis infectious by NCC, were not detected in some patients is due to the age group with the highest incidence have no aggregated vascular risk factors. The cerebrovascular complications are predominantly associated with the prevalence of the CC especially in the basal cisterns and associated arachnoiditis of variable degree [133, 135-139] later we will discuss this aspect based on our experience and results. It is known that when cisticerci are confined to a small area with associated arachnoiditis and few changes in the CSF, these affect small blood vessels predominantly penetrating arterioles causing 
infarctions very similar to the lacunar infarctions of the basal ganglia which did not differ from those caused by arteriopatías or microateromas. [94] The most severe form of vasculopathy infectious for NCC is observed when the CC spreads through the SAE with major alterations of the LCR and a chronic evolution of the disease. The neurovascular syndrome $(\mathrm{SNv})$ is usually the first manifestation of the focal SANCC that produces unique infarcts (90 \%), which often have a good prognosis. [94] In contrast, many patients have nonvascular complications (including intracranial hypertension and a progressive neurological impairment) when the NCC is diffusely extended in the CNS, whereas the SNv occurs only late in the course of the disease and has a grim forecast. [94] We have not found in the reviewed medical literature references related to the SANCC (See figure 4) and cerebrovascular complications in patients with HIV/AIDS.

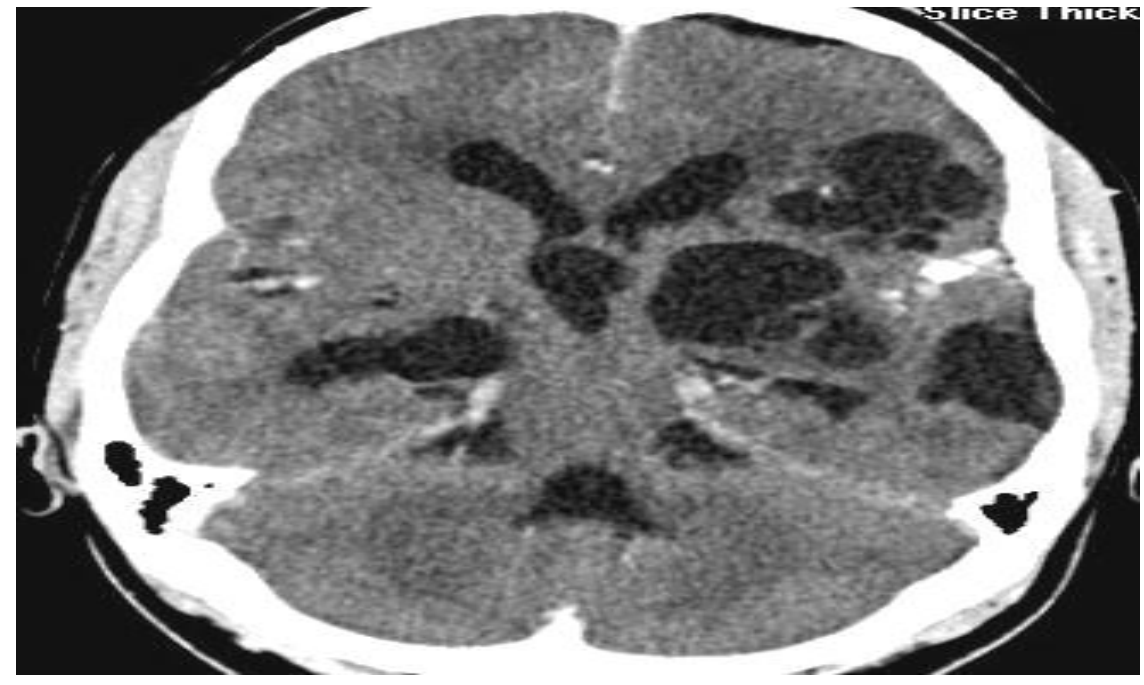

Figure 4. Racemose cystic lesions in left frontal and both temporal lobes. Intraventricular cyst causing obstructive hydrocephalus.

The SANCC also has some different features in the South African patient due to their frequent association with HIV infection. As is known, scattered $\mathrm{Ct}$ in the SAE cause the most severe forms of infectious vasculitis when evolve toward the chronicity [ 94], although no one knows the exact prevalence of this problem. [ 16] In our study we were able to determine that the risk to present an ischemic infarct is almost three times higher in patient with SANCC compared with the patient with intraparenchymal NCC and this risk increase more than seven times if the patient is HIV-positive. Therefore you have to exhaust all the possibilities of deworming to avoid cerebrovascular complications. [16]

\subsubsection{Intraspinal NCC}

The intra-spinal NCC (ISNCC) presentation include: Intra-medullary NCC (IMNCC) and extra-medullary NCC (EMNCC). The ISNCC is rare and there are only 45 cases reported in 
medical literature. Its frequency varies between 7 and $5.8 \%$ and its incidence is very low but six times more on that in axial medullary. [140, 141] Other authors in 2002 reviewed of 95 published cases of medullary cysticercosis since 1856. [142]

Its clinical manifestations are the result of the presence of CC in the intra-spinal canal i.e. the space between the meninges of the spinal canal.[143] Other authors have found up to 200 cases reported in the international medical literature before the year 2001, [144] this low prevalence of the IMNCC is explained by the fact that the blood supply to the spinal cord is 100 times less than the blood flow to the brain $[145,146]$ and the Ct usually comes to the region's best irrigated. Most of the times the symptoms of the ISNCC are secondary to the mass effect or the secondary edema, and among the most common can be found: spastic paraplegia, bladder incontinence, radicular pain or sexual impotence; the degree of commitment depends on the site which locate the lesion. [147] When there is an associated arachnoiditis (EMNCC) dominate the radicular pain and muscle weakness and when it affects the axial medullary then the predominant clinical feature is similar to the transverse myelitis characterized by sphincter dysfunction with motor and sensory signs below the level of the lesion. [148]

In ISNCC the subarachnoid damage can be secondary to its spread through the SAE, and the more usual imaging presentation is the EMNCC and arachnoiditis. The IMNCC presentation has been associated with hematogenous spread or through the spinal canal; the latter is seen as expansive lesions with a ring enhancement after contrast injection. [141] This presentation is extremely rare, and the lesions may be single or multiple, or even with the appearance of clusters. [149] When there is a degenerative process of the cystic lesion can also be seen this thickening in the ring of the cystic wall after the administration of contrast during a CT scan of the thoracic spine. [141,143, 147,150-152] It is equally unusual the damage of the spinal canal and the most frequent space occupies lesion to level EM. As we before-mentioned, on very rare occasions IMNCC is confirmed. [153] The differential diagnosis for the IMNCC presentation includes the IM abscess [154], other parasitic diseases such as hydatid cysts, neoplasias (ependymomas), traumatic lesions, sarcoidosis [155], arachnoid cysts [156], ependymal cysts [157] and neuroenteric cysts. [158] In the presentation EM include congenital cystic lesions (dermoides cysts); infectious diseases, demyelinating disorders, inflammatory or granulomatous, such as tuberculosis and sarcoidosis, and neoplasms. The region of provenance of the patient and the characteristics of the MRI images help to establish the difference. $[159,160]$ For this type of presentation there is a general consensus on the poor knowledge and limited experience of the problem. Surgical treatment is recommended alone or combined with APD and corticoids [133, 161], although others believe that surgery is the best treatment option for NCCIm counting with current techniques of microsurgery. [141] The recovery of patients with IMNCC with surgical treatment is fast, with ranges of a week with maximum recovery of 3 months after surgery. [162] Although they have also reported irreversible spinal injuries by NCCIm that logically do not recover with surgical intervention. [141] Finally, there are individual differences from the clinical point of view, imaging and of response to treatment according 
to the number and location of the lesions, that determine the characteristics of the presentations described $[117,161]$ and which are by describing such as: medullary central cord syndrome, medullary conus and the horsetail, when this happens. In the meantime, report of isolated cases continues to unfold with more or less variations between the same. $[162,163]$ We report a HIV patient presenting intraspinal calcified NCC and an associated tuberculosis of the spinal. [11] The clinical and imagenological features of NCC and TB of the spine in HIV-positive patients have not been previously reported. (See figure 5)

We have also seen patients with intramedullary granulomatous lesions and associated paravertebral calcified cysticercosis confirmed by biopsy and antigen/antibody cysticercosis serology test. (See figure 6)

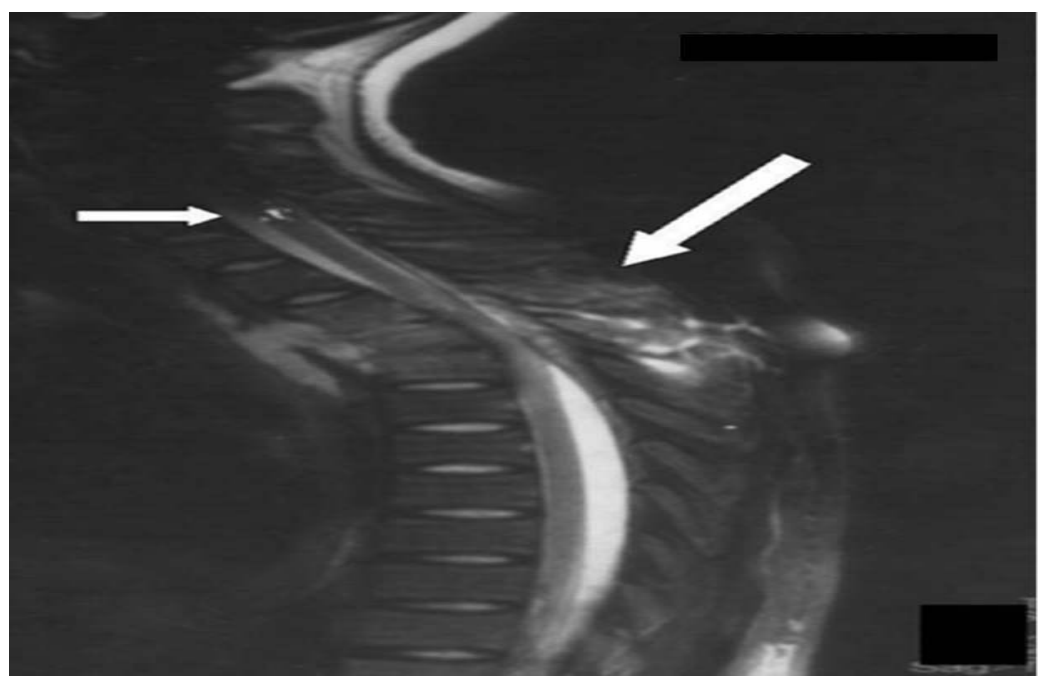

Figure 5. Shows calcified intramedullary calcified lesion and tuberculosis of the spine.

We will not discuss this observation in this chapter because we consider that this is just an anecdotal case that provides only casual interesting information. Some author thinks that EMNCC is explained by the downward migration of larvae from the brain to the spinal subarachnoid space and most larvae are expected to be stopped in the upper portions of the spinal canal due to peculiarities of the anatomy of the spinal cord; because it is hard to image cysticerci passing throughout foramen of Luscka and Magendie others authors support the hematogenous route. [11, 142, 163] Spinal intramedullary cysticercosis involving the conus medullaris is an extremelly uncommon clinical condition that may mimic an intramedullary tumor. It should be kept in mind in the differential diagnosis of intramedullary conus lesions and to rememeber that it can lead to irreversible neurological deficits if untreated.[164] Another clinical presentation is spastic paraplegia in patients presenting dorsal IMNCC but in some of them the neurological deficit may persist even after successful cyst excision. [165] Coexisting intramedullary schwannoma with intramedullary cysticercus has been reported. [166] 


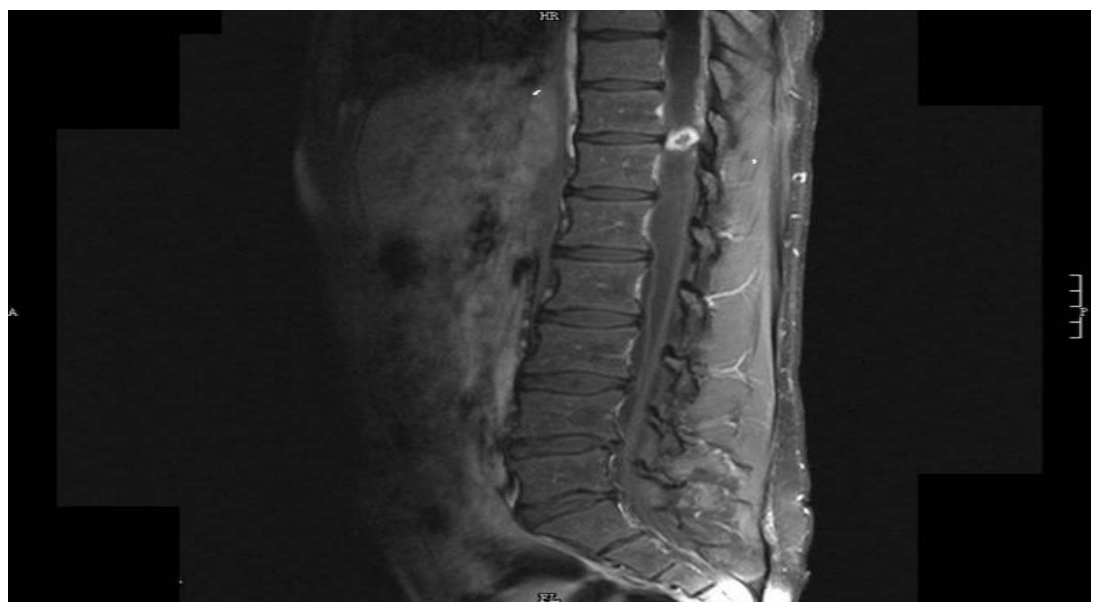

Figure 6. Multiplanar, multisequence MRI of the spine with IV contrast: Shows intramedullary ring enhancing lesion at the level of T11/T12 with enhancement of the meninges and nerve roots due to tuberculous radiculomyelitis, tuberculoma and calcified cysticercosis in the paravertebral muscles.

\section{Disseminated cysticercosis}

In the chapter entitled: "What is a low frequency of the disseminated cysticercosis suggests that neurocysticercosis is going to disappear?" Our readership will find detailed information about this uncommon presentation of cysticercosis. Therefore in this chapter we are going to mention only some remarkable issues.

Disseminated cysticercosis (DCC) was reported in 1912 by doctors of the English Navy stationed in India. An intensive search in PubMed revealed 22 cases reported by Wadia and collaborators in 1988 and only 16 additional cases were reported until 2006. [167] Two years later Bhalla et al., (2008) argued that fewer than 50 cases have been reported in the international medical literature most of them from India. [168] The characteristic features of the DCC is epilepsy, subcutaneous cysticercosis, the pseudo-hypertrophy in the four members and the allocation of any other organ or system. [164] However, a manifestation fairly typical of the DCC may be a subcutaneous cyst that occurs as an asymptomatic nodule. These subcutaneous nodules can be sliders in the muscle and measure up to $1.5 \mathrm{~cm}$. (See figure 6) In the case of patients who have had for more than 5 years cysticerci, these cysts are calcified. [169] Finally, there are individual differences from the clinical point of view, imaging and of response to treatment according to the number and location of the lesions, that determine the characteristics of the described presentations. $[117,160]$ Neurocysticercosis is always present in patients with DCC.

\section{Other uncommon presentations of neurocysticercosis}

The unusual location of the cysts may result in uncommon manifestations mimicking a host of neurological disorders. Thus, a high level of suspicion should be kept for NCC, especially 
in endemic zones and developing countries. Uncommon clinical presentations that demonstrate the spectrum of pleomorphism of NCC include extrapyramidal disease (parkinsonism and focal dystonia), Kluver-Bucy syndrome, Weber's syndrome, dementia and cortical blindness,[170] other authors include dorsal midbrain syndrome, isolated bilateral ptosis, papillitis, cerebral hemorrhage, painful cervical radiculopathy, progressive swelling of arm, paraplegia due to intramedullary cyst, third ventricular cyst, dystonia and nominal aphasia masquerading as transient ischaemic attacks, [171] and an associated pachymeningitis of the cervical spinal cord.[172]

\subsection{Brainstem neurocysticercosis}

\subsubsection{Midbrain, pons and medulla oblongata NCC}

In vertebrate anatomy the brainstem (or brain stem) is the posterior part of the brain, adjoining and structurally continuous with the spinal cord. The brain stem provides the main motor and sensory innervation to the face and neck via the cranial nerves. This is an extremely important part of the brain as the nerve connections of the motor and sensory systems from the main part of the brain to the rest of the body pass through the brain stem. This includes the corticospinal tract (motor), the posterior column-medial lemniscus pathway (fine touch, vibration sensation and proprioception) and the spinothalamic tract (pain, temperature, itch and crude touch). The brain stem also plays an important role in the regulation of cardiac and respiratory function. It also regulates the central nervous system, and is pivotal in maintaining consciousness and regulating the sleep cycle. The brain stem has many basic functions including heart rate, breathing, sleeping and eating. It is usually described as including the medulla oblongata (myelencephalon), pons (part of metencephalon), and midbrain (mesencephalon).Less frequently, parts of the diencephalon are included.

Isolated brainstem involvement in patients who have neurocysticercosis is rare, usually, it occurs in association with disseminated forms of cysticercosis and some patients can present acute midbrain syndrome responding well to corticosteroids [173,178-180] although tapering of corticosteroids should be performed very slowly in such cases [174] good response to albendazol therapy [175, 177, 178,179] and spontaneous resolution have been reported. The importance of recognizing this entity allows to avoid unnecessary surgical intervention, empirical anti-tuberculous chemotherapy, [176] and to recommend a conservative approach to case management, including observation. [175] The segment of the brainstem most frequently affected by the larval stage of the $T$ solium is the midbrain, followed by the pons and in some anecdotal cases the medulla oblongata. We will comment a little bit more about this presentation.

\subsubsection{Midbrain neurocysticercosis}

The midbrain or mesencephalon is a portion of the central nervous system associated with vision, hearing, motor control, sleep/wake, arousal (alertness), and temperature regulation. 
Anatomically, it comprises the tectum (or corpora quadrigemina), tegmentum and the cerebral peduncles, as well as several nuclei and fasciculi. Caudally the mesencephalon adjoins the pons (metencephalon) and rostrally it adjoins the diencephalon (Thalamus, hypothalamus, etc.). The midbrain is located below the cerebral cortex, and above the hindbrain placing it near the center of the brain. The clinical features of the midbrain neurocysticercosis (MIDNCC) could be summarized as follows:

\section{Pretectal syndrome}

The pretectal area, or pretectum, is a midbrain structure composed of seven nuclei and comprises part of the subcortical visual system. Through reciprocal bilateral projections to the retina, it is primarily involved in mediating pupillary light reflex, the optokinetic reflex, the accommodation reflex, and temporary changes to the circadian rhythm. In addition to the pretectum's role in the visual system, the anterior pretectal nucleus has been found to mediate somatosensory and nociceptive information. Parinaud's Syndrome, also known as a dorsal midbrain syndrome (Pretectal syndrome) is a group of abnormalities of eye movement and pupil dysfunction. It is caused by lesions of the upper brain stem and is named for Henri Parinaud (1844-1905), considered to be the father of French ophthalmology.

As before-mentioned, isolated brainstem involvement in patients who have neurocysticercosis is rare and symptoms and signs of MIDNCC can vary from one reported patient to another according to the exact location of T solium NCC. [174,175,181,182]

The symptoms of NCC of the pretectal area are nonspecific, but abnormal pupils, vertical gaze limitation, disjunctive horizontal and vertical eye position, lid retraction, and convergence-retraction nystagmus can be seen.[181]

\section{Weber syndrome}

Superior alternating hemiplegia is usually a form of stroke characterized by the presence of an oculomotor nerve palsy and contralateral hemiparesis or hemiplegia but cases secondary to MIDNCC (acute onset right 3rd nerve palsy with left hemiplegia) has been reported. [176]

\section{Third cranial nerve palsy}

Oculomotor nerve palsy is an eye condition resulting from damage to the third cranial nerve or a branch thereof. As the name suggests, the oculomotor nerve supplies the majority of the muscles controlling eye movements. Thus, damage to this nerve will result in the affected individual being unable to move their eyes normally. In addition, the nerve also supplies the upper eyelid muscle (Levator palpebrae superioris) and the muscles responsible for pupil constriction (sphincter pupillae). The limitations of eye movements resulting from the condition are generally so severe that the affected individual is unable to maintain normal alignment of their eyes when looking straight ahead, leading to strabismus and, as a consequence, double vision (diplopia). In the chapter entitled: "Orbital cysticercosis.A challenger for neurologists, ophthalmologists, neuro-ophthalmologists, and general practitioner" more detailed information about extraocular muscle palsy due to cysticercosis is available. 
Isolated third cranial nerve palsy is usually due to vascular causes like posterior communicating artery aneurysm and it is rare in NCC and is usually caused by supratentorial or sub-arachnoid lesions with accompanying hydrocephalus or meningitis however patients presenting third cranial nerve palsy caused by neurocysticercosis involving the midbrain has been reported. [174, 183]

\section{Claude's syndrome}

Claude's syndrome is a distinctive brainstem syndrome characterized by ipsilateral third cranial nerve palsy with contralateral hemiataxia and is due to an intrinsic or extrinsic lesion in the midbrain. The most common cause of Claude's syndrome is ischemic stroke on the midbrain however one patient presenting Claude's syndrome secondary to MIDNCC is reported. Therefore, if we encounter Claude's syndrome, we should consider neurocysticercosis infection as one of the etiologic factors [179]

\section{Superior divisional oculomotor nerve palsy}

Superior divisional oculomotor nerve palsy caused by intrinsic brain stem disease occurs rarely. The first case of midbrain neurocysticercosis presenting as isolated superior divisional paresis of the oculomotor nerve was communicated by Chotmongkol et al,. in 2006. [177] They reported a 25-year-old woman presented with acute onset of headache and ptosis-upgaze palsy of the right eye. This is an anecdotal case but serve to keep in mind MIDNCC for the differential diagnosis in similar cases.

\section{Sudden-onset ptosis [184]}

Sudden onset of ptosis secondary to MIDNCC was identified in 2008 and the first two children were informed to the medical literature by Singhi et al. [184] Recently Naphade et al., [180] reported the case of a 45-year-old woman who presented with acute onset of bilateral symmetrical ptosis with no other neurological deficit. Her imaging revealed a single cystic ring-enhancing lesion with perilesional oedema in the midbrain suggestive of NCC.

\subsubsection{Pontine neurocysticercosis}

The pons is a structure located on the brain stem, named after the Latin word for "bridge" or the 16th-century Italian anatomist and surgeon Costanzo Varolio (Pons Varolii). It is cranial to the medulla oblongata, caudal to the midbrain, and ventral to the cerebellum. In humans and other bipeds this means it is above the medulla, below the midbrain, and anterior to the cerebellum. This white matter includes tracts that conduct signals from the cerebrum down to the cerebellum and medulla, and tracts that carry the sensory signals up into the thalamus. The pons measures about $2.5 \mathrm{~cm}$ in length. Most of it appears as a broad anterior bulge rostral to the medulla. Posteriorly, it consists mainly of two pairs of thick stalks called cerebellar peduncles which connect the cerebellum to the pons and midbrain. The pons contains nuclei that relay signals from the forebrain to the cerebellum, along with nuclei that deal primarily with sleep, respiration, swallowing, bladder control, hearing, equilibrium, taste, eye movement, facial expressions, facial sensation, and posture. The pons is implicated in sleep paralysis, and also plays a role in generating dreams. 
Clinical features of pontine neurocyticercosis (PNCC) also depends of different locations of the $\mathrm{T}$ solium at the pontine level such as:

\section{Internuclear ophthalmoplegia}

Internuclear ophthalmoplegia (INO) is a disorder of conjugate lateral gaze in which the affected eye shows impairment of adduction. When an attempt is made to gaze contralaterally (relative to the affected eye), the affected eye adducts minimally, if at all. The contralateral eye abducts, however with nystagmus. Additionally, the divergence of the eyes leads to horizontal diplopia. That is, if the right eye is affected the patient will "see double" when looking to the left, seeing two images side-by-side. Convergence is generally preserved. Clinical presentations of INO can be divided into: unilateral INO, bilateral INO, and one-and-a-half syndrome in a similar descending frequency. [185] Perhaps the more difficult clinical diagnosis to perform is the One-and-a-half syndrome (OAHS). It is a neurological disorder of the extra ocular movements characterized by conjugate horizontal gaze palsy in one direction and internuclear ophthalmoplegia (INO) in the other. The commonest cause of the syndrome is a vascular lesion on the basilar territory followed by demyelinating lesions of the brainstem usually affecting the paramedian pontine reticular formation unilaterally or due to lesions on the abducens nucleus on one side, with interruption of internuclear fibbers of the ipsilateral medial longitudinal fasciculus after it has crossed the midline from its side of origin in the contra lateral abducens nucleus causing failure of adduction of the ipsilateral eye. [186]

In 2004, we proposed a new classification for OAHS based on our finding in patients with NCC and cerebrovascular diseases and we described the clinical features of One-and-a-half "plus" syndrome. We found patients with other combinations that can be called as: Fiveand-a-half syndrome $\left(1 \frac{1}{2}+4\right.$-throclear nerve), Seven-and-a-half syndrome $\left(\begin{array}{lll}1 & 1 / 2 & +6-\end{array}\right.$ abducens) or Eleven-and-a-half syndrome (1 $1 / 2+7$-facial nerve +3 -oculomotor nerve) due to racemose NCC, and midbrain lesions related to NCC. However we honestly considered at that time and even today that a generation of novel arithmetic combinations will bring more confusion than clarity to this problem and will increase unnecessarily the long list of different names of neuro-ophthalmological disorders, therefore we concluded that adding the term "plus" was good enough to distinguish these conditions from the typical OAHS. [186] Five years later Ranjith et al [178] studied an 18-year-old male presented with a history of sudden-onset diplopia of 1-week duration and blurring of vision. He had no history of headache, fever, seizures, walking difficulty, previous head injury, diabetes or hypertension. There was no history of a similar episode in the past. Diplopia was found to increase while looking to the left. Findings from general examination were normal. The left eye was deviated outward, and the right eye was central in primary gaze. There was a weakness of adduction in the left eye and paralysis of all conjugate horizontal eye movements in the right eye. The left eye also showed nystagmus while the patient attempted left lateral gaze. Vertical eye movements were normal, and no ocular bobbing was observed. There was no long tract sign, and the cerebellar system was normal. They confirmed OAHS secondary to PNCC. 


\section{Simulating cystic tumor}

Characterized by focal neurological signs and clinical manifestation of intracranial hypertension including abducens palsy among other features. Cases have been reported [187]

\section{Hemifacial spasm}

Ipsilateral hemifacial spasm and associated bladder incontinence and confusional state secondary to PNCC has been reported [173]

\section{Isolated facial myokymia}

In patients presenting a history of continuous rippling and quivering movements of their hemiface suggestive of myokymia, a diagnosis of PNCC should be taking into account. The first well documented patient was reported in the medical literature by Bhatia et al in 2008 [188]

\subsubsection{Medulla oblongata neurocysticercosis}

The medulla oblongata is the lower half of the brainstem. In discussions of neurology and similar contexts where no ambiguity will result, it is often referred to as simply the medulla. The medulla contains the cardiac, respiratory, vomiting and vasomotor centers and deals with autonomic, involuntary functions, such as breathing, heart rate and blood pressure.

The medulla neurocysticercosis (MENCC) is an extremely rare presentation of NCC and the main affected area is the lateral aspect of the medulla leading to: Lateral medullary syndrome (also called Wallenberg syndrome and posterior inferior cerebellar artery syndrome) which is characterized by sensory deficits affecting the trunk and extremities on the opposite side of the MEDNCC and sensory deficits affecting the face and cranial nerves on the same side of the lesion. Specifically, there is a loss of pain and temperature sensation on the contralateral (opposite) side of the body due to damage of the spinothalamic tract and ipsilateral side of the face including an absence of corneal reflex due to lesion of the spinal trigeminal nucleus. Clinical symptoms include ataxia secondary to damage of the inferior cerebellar peduncle, facial pain, vertigo and nystagmus due to lesion of Deiters' nucleus and the inferior vestibular nucleus, and possibly palatal myoclonus may be observed due to disruption of the central tegmental tract. Damage to the hypothalamospinal fibers disrupts sympathetic nervous system relay and gives symptoms analogous to Horner syndrome. If patients also start vomiting then the extension of the damage toward the area postrema (dorsal vagal complex) should be considered. Remember that the area postrema is located outside of the blood-brain barrier and connects to the nucleus of the solitary tract and other autonomic control centers in the brainstem, which may serve as the beginning of the pathway triggering vomiting in response to various emetic inputs. The MEDNCC causing Wallenber syndrome has been communicated by Garg in 1999. [189]

Other uncommon presentations of NCC may include: Bilateral trigeminal neuralgia secondary to racemous cysticercus of the cerebellopontine angle, [190] and bradycardia due to right cerebellar peduncle neurocysticercosis, [191] 


\subsubsection{Insula lobe neurocysticercosis}

In each hemisphere of the mammalian brain the insular cortex (often called insula, insulary cortex, Island of Reil or the insular lobe) is a portion of the cerebral cortex folded deep within the lateral sulcus between the temporal lobe and the frontal lobe. The insula is believed to be involved in consciousness and play a role in diverse functions usually linked to emotion or the regulation of the body's homeostasis. These functions include perception, motor control, self-awareness, cognitive functioning, and interpersonal experience. In relation to these it is involved in psychopathology.

The insular cortex is divided into two parts: the larger anterior insula and the smaller posterior insula in which more than a dozen field areas have been identified. The cortical area overlying the insula towards the lateral surface of the brain is the operculum (meaning "lid"). The Operculum, derived from Latin, meaning "little lid", refers to the cerebral cortex that covers the insula and is formed from parts of the enclosing frontal, temporal and parietal lobes. Operculum-insular cortex plays a role in the processing of nociceptive input. It has been convincingly established, over the past decade, that the human insular cortices are involved in processing both body feelings (such as pain) and feelings of emotion. Recently, however, an interpretation of this finding has emerged suggesting that the insular cortices are the necessary and sufficient platform for human feelings, in effect, the sole neural source of feeling experiences. [192]

Between the years 1999 and 2005 we studied a series of patients with NCC located in the lobe of the insula (INCC) confirmed by imagenology. All came from the epilepsy/NCC clinic and the neurology clinic of the Mthatha Hospital Complex. This study was designed for the screening of symptoms and clinical signs such as: dysphagia, dysarthria, attention deficit disorders, cardiovascular problems, and epileptic seizures.

All the patients underwent a CT scan of the brain and/or MRI, an ELISA test for the determination of antigens and antibodies of CC in serum and an electrocardiogram. For all patients a digital interictal EEG was performed based on, the 10-20 system and each study lasted about 20 minutes looking for focal or generalized alterations of the background rhythm or paroxysmal activity.

It was considered that the patient had difficulty swallowing liquids when they were choking or coughing after swallowing five cubic centimeters of water. In the first six month period of this study we explored the ability of the patients to differentiate between expressions of fear or disgust in photos or drawings that we show them for that purpose. Unfortunately many patients did not have the capacity to differentiate an expression of joy, fear or sadness; however we erroneously believe that this test did not work and it was eliminated from this study. In this research, special attention was given in the exclusion of patients with a history of other neurological diseases in addition to epilepsy, metabolic diseases of any type of ischemic heart disease or diseases causing difficulty in swallowing, the syndromes of Jervell-Lang -Nielsen, Romano-Ward and other causes of prolongation of the QT Segment. 
Two patients died and in the postmortem studies T solium cystic lesions were confirmed in the insular cortex. (See figure 7) The problems most frequently encountered were functional dysphagia, the visual and somato-sensory inattention, ECG alterations such as ST-segment depression greater than 0.1 millivolts by more than 80 milliseconds and elongation of the QT Segment (greater than 0.44 seconds).

In our series, disturbances of the language due to the NCC are very uncommon excepting some patients presenting ischemic stroke due to cysticercotic /HIV/AIDS vasculitis. It is even rare in patients presenting $\mathrm{T}$ solium cystic lesions in the motor or sensory language cortical regions. In patients with lesions of the insula with involvement of the superior temporal gyrus and the inferior parietal region, conductive afasias have been reported, [193] but we have not been able to identify any single patient with isolated disorders of the speech or spoken languages without stroke.

The insula of the right cerebral hemisphere may play an important role in the autonomic control of the heart and the electrocardiographic abnormalities of the heart are often transient, but represent a diagnostic problem sometimes indistinguishable from a myocardial infarction. Some alterations of the $\mathrm{T}$ waves may be suggestive of cardiac pathology, but are not specific so it is important to consider this situation to avoid inappropriate treatment.

In the year 2004, Colivichi et al. [194] designed a study to establish the relationship between the vascular ischemic brain damage at the level of the right insular lobe and cardiac arrhythmias and they concluded that this area of the brain exerts a controlling function of the visceral autonomic activity on the heart with prognostic implications. However, the cardiac signs found in our series such as: asystole and bradycardia may also be suggestive of cardiac dysfunction secondary to left insula as has previously been reported in patients with temporal lobe epilepsy [195-198] and confirmed in 2009 by Koseoglu et al.[199] The epileptic activity spreads through the limbic system with the involvement of the amygdala, hypothalamus, and thalamus. These, in turn stimulate the autonomic system at medullar level including the nucleus tractus solitarius and the nucleus ambiguous which generate sympathetic and parasympathetic discharges.[200]

In our first study the ictal manifestations found were: laryngeal constriction, oppression of the chest, paresthesia of peri-oral region, the feeling of suspension or floating and some taste disorders. The characteristics of the epileptic seizures in these patients could not be defined convincingly at that time, therefore few years later, the realization of a methodological design addressed primarily to achieve that goal was made. However as noted earlier in this study could not arrive at confident conclusions. Later we concluded that the INCC is characterized by a functional dysphagia, ECG alterations such as: ST-segment depression and especially a prolongation of the QT segment, atypical epileptic seizures, a slight spastic dysarthria, sensory lapses and cardiovascular disorders. [7, 15]

Finally, we would like to highlight that even when the clinical features of the lesions in the insula are known mainly from neurophysiological studies and by electrical stimulation of the insular cortex, our clinical findings were not previously reported in the international medical literature although some of them were confirmed later by other authors. [201-203] 


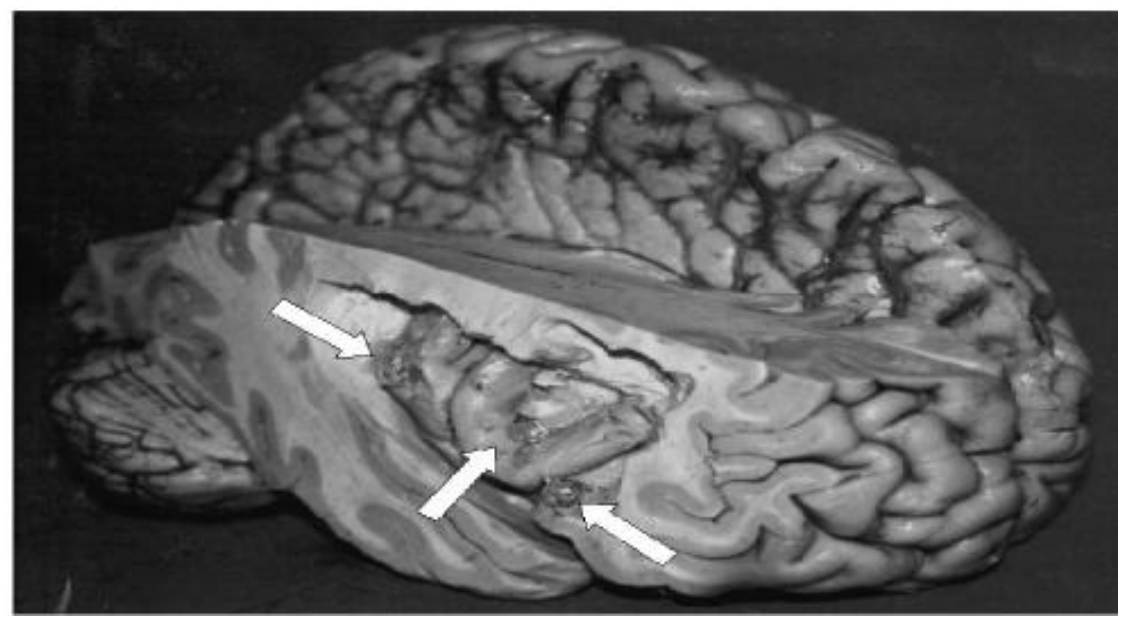

Figure 7. Right insular lobe with $\mathrm{T}$ solium cysticercosis in different stages. Unfortunately some cyst was damaged during disserting procedures.

In brief: patient with INCC may submit a functional dysphagia with visual and somatosensory inattention, signs of neurogenic heart and, ECG alterations such as ST-segment depression greater than 0.1 millivolts for longer than 80 milliseconds and elongation of the QT segment (greater than 0.44 seconds) and that special attention should be given to this mode of presentation by the serious complications that can be involved, including death.

The clinical features of epileptic seizures secondary to NCCI are characterized by paroxysmal feeling of laryngeal constriction, the functional dysphagia, and peribucal paresthesia. We must insist on the patient's interview about these symptoms if there is evidence of INCC in imagenology. Frequently, neither the patient nor the family or friends give importance to these symptoms and the situation is even worse when the patient is assisted by other doctor, another diagnosis is made and do not to pay too much attention is suggested especially if the seizures are sporadic and apparently banal. The diagnosis is based on the clinical confirmation of these manifestations as the conventional EEG with surface electrode is normal. $[7,15]$

\subsubsection{Middle fossa neurocysticercosis}

Apart from subarachnoid NCC, $T$ solium can also affect directly or indirectly midline anatomical structures such as: optic quiasm, hypothalamus, pituitary gland, and sella turcica.

\subsubsection{Optic quiasm NCC}

The optic chiasm (OCh) is the part of the brain where the optic nerves partially cross. Several important structures are located adjacent to the OCh. The supraclinoid branches of the internal carotid artery flank the OCh. The cavernous sinuses are lateral and inferior to 
the OCh. The frontal lobe of the brain lies above. The pituitary gland sits below in the sella turcica. The sella turcica is bounded in front by the tuberculum sellae and behind of the dorsum sellae. Behind the chiasm lies the floor of the third ventricle. Chiasmal syndrome is the medical term used to describe the various signs and symptoms that are associated with lesions of the OCh, manifesting as various types of blindness or impairment in the sufferer's visual field according on the location of the lesions along the optic nerve.

Optic NCC has been well described in the past and all interested readers can find more information in the chapter entitled: "Orbital cysticercosis. A challenger for neurologists, ophthalmologists, neuro-ophthalmologists, and general practtioners" in this book. However optic chiasm NCC (OChNCC) caused by intra-chiasmatic cysticercosis has not been reported up to date. It's known that the clinical features of the OCh are caused by inflammatory processes secondary to cysticercotic vasculitis [204] or by released pro-inflammatory elements when close by cysticerci are dying. Neurocysticercosis may cause bitemporal hemianopsia due to chiasmatic compression secondary to obstructive hydrocephalus. [205]

\subsubsection{Intra-Sellar turcica neurocysticercosis}

The sella turcica is a midline depression in the sphenoid bone which contains the anterior and posterior lobes of the pituitary gland and the distal portion of the pituitary stalk. It is covered by a dural reflection, the diaphragm sellae. Above this lies the suprasellar cistern, which contains the supraclinoid carotid arteries and the optic tract, OCh, and nerves, and through which travels the pituitary stalk, Lateral to the sella turcica are the cavernous sinuses containing the carotid arteries, cranial nerves III, IV, and VI, and the first two divisions of the fifth cranial nerve. Anteriorly, the sella turcica is bound by the tuberculum sellae and anterolaterally by the anterior clinoid processes, Anteroinferiorly, the foramen rotundum conducts the maxillary branch of cranial nerve V. Posteriorly, there are the smaller posterior clinoid processes, the dorsum sellae, and the interpeduncular cistern containing cranial nerves III and IV. Inferiorly, the sella turcica has a thin floor of cortical bone, below which lies the air-containing sphenoid sinus. The sinus is extremely variable in size. Adjacent to the posteroinferior aspect of the cavernous sinus lies a Meckel's cave, containing the gasserian ganglion. Immediately below and lateral to the gasserian ganglion, the third branch of the fifth cranial nerve exits through the foramen ovale.

In 1915, Kufs described a woman in whom destruction of the pituitary by one of multiple basilar cysts was found at autopsy. The diagnosis was not suspected antemortem, and the patient had findings that may have been related to pituitary insufficiency. [206] In 1955, panhypopituitarism was diagnosed by Dickinson [207] in a British soldier who had served in India and developed epilepsy with X-ray evidence of cysticerci in the legs and a distorted pituitary phase CT scan of the brain was not available at that time. The case reported by Briceflo et al. (1961) was one of 97 cases of cysticercosis found among 2 ,767 routine autopsies over a 6-year period in a large Mexican hospital. Clinical data were not presented, and the authors did not record whether the patient had other lesions elsewhere in the CNS. [209] A fourth report describes a patient with cysticercosis masquerading as a pituitary 
tumor, but this probably represented enlargement and an erosion of the sella secondary to increased intra cranial pressure. [210] Therefore the fourth well documented patient with sella turcica neurocysticercosis (STNCC) was studied by Prosser et al in 1978. They reported a 42-year-old woman from El Salvador presented with arthralgias and headache. She was found to have an enlarged sella with an intrasellar mass. Transsphenoidal exploration of the sella revealed a cysticercus, the cyst was successfully removed and normal pituitary function was retained. These authors recommend that cysticercosis be considered in the differential diagnosis of any patient from an endemic area who presents with a mass lesion anywhere in the CNS, including intrasellar masses. [210] Few years later other authors reported cases presenting disturbances in both visual acuity and visual fields and other considerations were made. [211,212]

As a general rule, for patients from endemic areas presenting chiasmatic syndrome and hormonal disturbances to rule out STNCC is mandatory. Other authors have similar opinions. [210, 213-216]

Although NCC damages sellar structures with direct compression by large cysts, extension through the basal cisterns and third ventricle with focal arachnoiditis can result as an inflammatory response. Taking into consideration that the sellar region and the basal cisterns contain many vascular and CNS structures that are separated by only a few millimeters increasing the possibility that different pathologic entities could affect them simultaneously then analysis of imaging findings and knowledge of the varied clinical presentations of NCC are important to detect cases of sellar involvement in patients with unexplained visual loss or atypical cystic lesions in the sella, especially in endemic countries. [213] As in other locations in the brain, the parasite can affect the sellar structures through diverse mechanisms, ranging from direct or indirect invasion to a severe local inflammatory response [217-218] Although direct invasion of the sella turcica by the NCC vesicle affecting the hypophysis is the most commonly described form in the literature [206-212] and is often confused with the most common tumors of the area (eg, cystic adenoma and craniopharyngioma). The absence of clinical suspicion of STNCC usually results in surgical treatment of the lesions and postoperative diagnosis of the NCC with variable clinical results. [213]

A 7-year-old child presented with polyuria and polydipsia for 1 year due to a small cystic lesion in the proximal pituitary stalk was also reported in the medical literature. [214] And three patients presenting hypopituitarism secondary to the NCC have been reported as well. [216]

\subsubsection{Hypothalamic neurocysticercosis}

The hypothalamus is a portion of the brain that contains a number of small nuclei with a variety of functions. One of the most important functions of the hypothalamus is to link the nervous system to the endocrine system via the pituitary gland (hypophysis). The hypothalamus is located below the thalamus, just above the brain stem. In the terminology of neuroanatomy, it forms the ventral part of the diencephalon. All vertebrate brains contain a hypothalamus. In humans, it is roughly the size of an almond. 
The hypothalamus is responsible for certain metabolic processes and other activities of the autonomic nervous system. It synthesizes and secretes certain neurohormones, often called hypothalamic-releasing hormones, and these in turn stimulate or inhibit the secretion of pituitary hormones. The hypothalamus controls body temperature, hunger, thirst, fatigue, sleep, and circadian cycles. In mammals, the axons of magnocellular neurosecretory cells of the paraventricular nucleus and the supraoptic nucleus, which contain oxytocin and vasopressin (also called antidiuretic hormone), comprise the posterior pituitary. Parvocellular neurons of the paraventricular nucleus contain neurons that release corticotropin-releasing hormone and other hormones into the hypophyseal portal system where these hormones diffuse to the anterior pituitary.

The hypothalamus is thus richly connected to many parts of the central nervous system, including the brainstem reticular formation and autonomic zones, the limbic forebrain (particularly the amygdala, septum, diagonal band of Broca, and the olfactory bulbs, and the cerebral cortex). The hypothalamic-pituitary-adrenal axis (HPA or HTPA axis), also known as the limbic-hypothalamic-pituitary-adrenal axis (LHPA axis) and, occasionally, as the hypothalamus-pituitary-adrenal-gonadotropic axis, is a complex set of direct influences and feedback interactions among the hypothalamus, the pituitary gland (a pea-shaped structure located below the hypothalamus), and the adrenal glands.

Hypothalamic neurocysticercosis (HTNCC) is another extremelly uncommon presentation of NCC and the most common clinical features of best documented patient are characterized by: obesity, galactorrhea and central diabetes insipidus (polyuria without solute diuresis), and panhypopituitarism due to an associated pituitary gland involvement can also be present.[207,217, 219-222, 224] It has been established that intracranial hypertension "per se" does not generate changes in the hypothalamopituitary axis function. [219]

At a Uberaba Teaching Hospital in Brazil, a total of 1.596 autopsies performed between 1974 and 1997 were studied. The study found a diagnosis of cysticercosis in 53 autopsies (3.3\%) and in two obese patients with NCC the lesions were located in the ventromedial nucleus of the hypothalamus. [220]

Other authors also divided the unusual manifestations of neurocysticercosis into: intraventricular, subarachnoid, spinal, orbital, intraparenchymatous, and reactivation of previously calcified lesions and they reported frequencies of $15.69 \%$ of intraventricular presentations, subarachnoid: $11.63 \%$; spinal: $3.49 \%$; orbital: $0.58 \%$ and reactivated lesion: $0.58 \%$ and the frequencies for association of intraventricular and intraparenchymatous: 6.98\%; association of subarachnoid and intraparenchymatous: 3.49 ; and association of subarachnoid and intraventricular: $2.32 \%$. [225] but they did not include other presentations already mentioned in this chapter.

\subsubsection{Solitary cysticercus granuloma}

The solitary cysticercus granuloma (SCG) is considered the most frequent type of NCC in India and many other Southeast Asian countries and these lesions are the most frequent 
neuroimaging abnormality seen as: less than $20 \mathrm{~mm}$ ring-enhancing lesion in patients with new-onset epilepsy. [223] However, in our region SCG is not the most frequent presentation of NCC and compared with the prevalence of multiple active and the calcified intraparenchymal NCC which is highest, SCG is relatively uncommon probable related to unknown factors.

\subsubsection{Sinus thrombosis}

Only one patient presenting lateral sinus thrombosis secondary to NCC has been reported in the medical literature up to date. [226]

\section{Extracraneal cysticercosis}

Taenia solium cysticercosis can invade almost all extracraneal anatomical structures in the head excepting skin, nasal cavity, paranasal sinus, bone tissue and the periostium.

When a temporalis muscle is involved, clinical presentation can be a temporal headache. Two woman who complained of subacute onset of left temporal pain and another complaining headache due to cysticercosis of the temporalis muscle have been reported. $[227,228]$

\subsection{Ocular cysticercosis}

Ocular cysts are mostly vitreous or may be found in subretinal locations. Cysts can impair vision by floating in the eye and can lead to blindness by causing retinal detachment. Visualization of cysts via fundoscopy may be diagnostic of the disease.

We dedicated a complete article for this issue and interested readers can find detailed information in the chapter entitled: “Orbital Cysticercosis. A challenger for neurologists, ophthalmologists, neurophthalmologists, and general practitioners"

\subsection{Facial cysticercosis}

We found facial cysticercosis in a patient presenting disseminate subcutaneous and muscular cysticercosis with cardiac involvement and NCC. [10] A cystic lesion on the right cheek and in the maxillofacial region have been also reported. [229, 230] A photo of patient showing a nodular lesion in the left hemiface at the zigomatic arch level that was removed by surgical procedures and histological examination confirmed $\mathrm{T}$ solium cysticercosis can be seen in a previous chapter.

\subsection{Buco-lingua-pharyngeal cysticercosis}

\subsubsection{Oral cysticercosis}

As other before-cited locations of cysticercosis this one, is also extremely uncommon. Patients presenting lesion in the lips, [231, 232] oral cavity, [233] oral mucosa, [232] and in 
the gums [232] due to cysticercosis have been well documented. In all cases clinical manifestations are related to the size of the nodule lesion and good response to antiparasitic medication is the rule.

Cysticercus in the tongue can be present up to $50 \%$ in porcine cysticercosis. However in human beings only anecdotal cases have been reported. [232, 234]

\subsection{Parotid gland cysticercosis}

Involvement of the parotid gland is manifest by a mass effect, masquerading as a salivary gland neoplasm or mild swelling with occasional aching sensation and headache, and features resembling acute parotitis [235-238] Parotid gland cysticercosis can be associated with NCC [237] or presenting as a solitary extracranial cysticercosis of the parotid gland. [238] In solitary lesions final diagnosis is based on fine needle aspiration cytology and immunological investigations and in patients with an associated NCC antigen/antibody tests for T solium cysticercosis can be useful.

\subsection{Neck cysticercosis}

Subcutaneous cysticercosis in the neck is usually part of the disseminated cysticercosis and it does not constitute an independent clinical entity by itself because its clinical features are similar to another subcutaneous location. [10] We studied one patient with this condition who is cited in the chapter entitled: "Orbital cysticercosis. A challenger for a neurologist, ophthalmologist, neurophthalmologists, and general practitioners". Other uncommon presentations of cysticercosis around the neck are: thyroid cysticercosis (one patient is from our region), [239, 240] cricothyroid muscle cysticercosis, [241] pharyngeal cysticercosis, first described in South Africa, [242] submandibular lymphadenopathy cysticercosis in a 7-y-old girl presented with seizures and a right submandibular lymph node enlargement confirmed by fine needle aspiration cytology [243] and cervical lymphadenopathy cysticercosis [244] cysticercosis of submandibular duct [245] and isolated cysticercosis of the sternocleidomastoid [246] were also reported.

\section{Truncal cysticercosis}

\subsection{Thoracic cysticercosis}

The thoracic cavity (or chest cavity) is the chamber of the human body (and other animal bodies) that is protected by the thoracic wall (thoracic cage and associated skin, muscle, and fascia) which can be infected by isolated $\mathrm{T}$ solium cysticercosis or disseminated cysticercosis as it has been reported in South African patients. [10, 240, 242, 247, 251 ] and others. [241, 252-255] Anatomical structures within the thoracic cavity include: structures of the cardiovascular system, including the heart where cardiac cysticercosis can be seen. $[10,247,248,256-267]$ Parasitic diseases may involve various anatomic structures of the heart which can be manifested clinically as myocarditis, cardiomyopathies, pericarditis, or pulmonary hypertension in many resource-constrained settings. [263] Other structures are: 
great vessels and the trachea but up to date, tracheal cysticercosis is seen only in porcine cysticercosis. [265] Esophageal cysticercosis has not been described; $T$ solium thymic cysticercosis has not been reported as yet. In the other hand; vagus nerves, the paired sympathetic chains, lymphatic and the thoracic duct cysticercosis have not been well documented in the medical literature neither. Finally we would like to emphasize that pericardial cysticercosis is also extremely uncommon and has been mentioned in the international medical literature occasionally. [264,266] Other intra-thoracic anatomical structures are: lungs where pulmonary cysticercosis has been communicated. [240, 249, 250] Pulmonary infiltration with eosinophilia is a disease entity characterized by lung disease and eosinophilia its commonest causes are tuberculosis, parasitic infestations, malignancy and connective tissue disorders. The first report about pleural effusion and subcutaneous cysticercosis in a 2 year old child is made by Salaria et al. in 2001. [268] In adults pleural effusion is the commonest presentation of pleural cysticercosis. [269, 270]

\subsection{Breast cysticercosis}

In women, the breasts overlay the pectoralis major muscles and usually extend from the level of the second rib to the level of the sixth rib in the front of the human rib cage; thus, the breasts cover much of the chest area and the chest walls. At the front of the chest, the breast tissue can extend from the clavicle (collarbone) to the middle of the sternum (breastbone). At the sides of the chest, the breast tissue can extend into the axilla (armpit), and can reach as far to the back as the latissimus dorsi muscle, extending from the lower back to the humerus bone (the longest bone of the upper arm). As a mammary gland, the breast is an homogeneous anatomic structure composed of layers of different types of tissue, among which predominate two types, adipose tissue and glandular tissue, which affects the lactation functions of the breasts. The blood supply to the breast is derived from 3 sources. The predominant supply of blood comes from the perforating branches of the internal mammary arteries, derived from the internal thoracic artery. The breast is supplied by the lateral thoracic and thoracoacromial arteries (branches of the axillary artery) as well as posterior intercostal arteries (branches of the thoracic aorta). Apart from breast pain, fibrocystic change, nipple discharge, tumor, bacterial and fungal infection and Paget's disease; breast can also be infected by T solium cysticercosis. Some patients can present from mastalgia, hyperprolactinaemia [271] and painless mobile swelling (lump) in the breast [272] to no clinical manifestations. [273]

In places where cysticercosis is frequent the before mentioned presentations are rare while in countries where cysticercosis had been exceedingly rare (i.e. Malaysia), with only one case of neurocysticercosis diagnosed during post-mortem in 1934 and another one diagnosed ante-mortem [274] any presentation is uncommon.

\subsection{Limbs cysticercosis}

Limbs cysticercosis may be isolated in the biceps brachii, deltoid, thigh, elbow, forearm, triceps, gluteal muscles [275-290] or as part of disseminated cysticercosis. [254, 291-296] The 
clinical features depend on the location of the cyst, the cyst burden, and the host reaction but most of patients' present painless, rubbery nodules around $2 \mathrm{~cm}$ in diameter, which do not carry any risk to the patient's health or can present pseudotumor, mass, pseudohypertrophy [295-298] and myalgias. [298] A positive diagnosis is established solely by incision and examination of the interior, where the parasite will be found. In the other hand, the role of ultrasonographic (USG) studies in the diagnosis of isolated soft tissue cysticercosis has been also confirmed. [295] The most common USG appearance is that of a cyst containing a scolex within and with surrounding abscess. The second most common appearance reported is that of a cyst containing a scolex within and with surrounding edema and the least common appearance is that of an irregular cyst with no scolex within and with surrounding edema. [295] Fine needle aspiration cytology [296] and even mitochondrial DNA analysis of extremely calcified cysts have demonstrated a good efficacy. [288]

We found a good response to $100 \mathrm{mg} / \mathrm{kg}$ of praziquantel for a day [292] but in most patients albendazole is the medication of choice.

Cysticercosis of the flexordigitorum profundus muscle producing flexion deformity of the fingers and cysticercosis of the tendon sheath of Tendoachilles have been reported. [300, 301]

Only one patient with cysticercosis presenting as an ulnar entrapment neuropathy due to a compressive mass in the flexor digitorum profundus has been reported. In this case magnetic resonance imaging suggested an inflammatory mass compressing the neurovascular bundle and the final diagnosis was confirmed by histologic examination. [302]

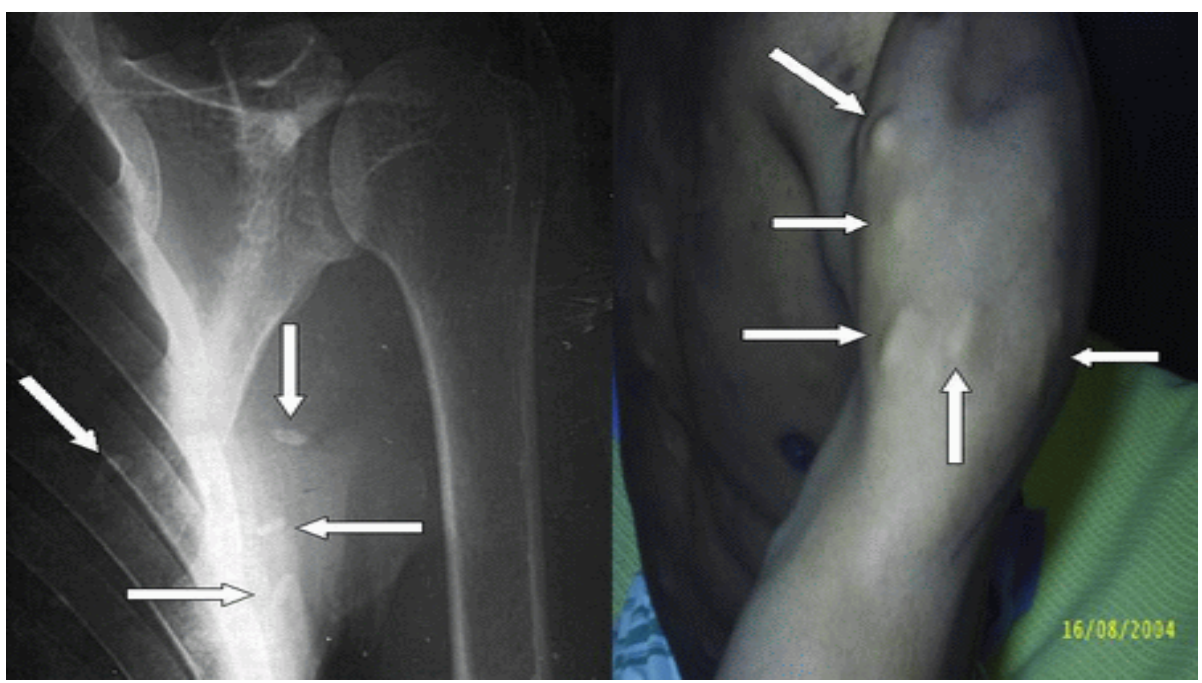

Figure 8. Subcutaneous and intramuscular cysticercosis in the proximal region of the limbs predominantly 
The most common location for soft tissue cysticercosis is in the skeletal muscles of the upper extremities (33. \%) as we show in the next figure. , and the least common sites for isolated muscular cysticercosis are the back, buttock and cheek, which accounted for $3 \%$ each [287].

\subsection{Monoarticular cysticercosis}

A joint is the location at which two or more bones make contact. They are constructed to allow movement (except for skull bones) and provide mechanical support to the body. A joint disorder is termed an arthropathy, and when involving inflammation of one or more joints the disorder is called: arthritis.

Arthropathies are called polyarticular when involving many joints and monoarticular when involving only one single joint how can happens cysticercotic arthropathy. Fortunately it is another very rare condition. Kurrein and Vickers [303] reported a former regular soldier who had served in India before the Second World War. He was in 1953-1955 diagnosed as suffering from cysticercosis affecting the brain and spinal cord as well as the muscles. Twenty years later he was found to have sustained severe damage to the lumbar spine, eventually proved due to cysticercosis involving the bones, joints and psoas muscles. The problem of why and how the disease remained active 40 years after the initial exposure remains unexplained. Searches of the literature and enquiries from appropriate specialists have failed to produce any record of similar cases. Kumar e al., [304] studied a 62-years old man presented with complaints of pain in the large peripheral joints with limitation of movement for two months. Fine needle aspiration cytology of the nodular eruptions over joints demonstrated negatively birefringent needle shaped crystals while that of calcific lesion in soft tissue demonstrated cysticercus cellulose with scolex. However the majority of the researchers that we have consulted, agree that the diagnosis of joint cysticercosis in this patient demonstrates some doubts though cannot be rejected.

The last report is made by Banu and Veen. [305] They studied an immunocompetent patient with disseminated cysticercosis who had involvement of the brain, subcutaneous tissues, lungs and skeletal muscles and presented with arthritis. This patient was otherwise asymptomatic in spite of the extensive involvement of multiple organs.

\section{Abdominopelvic cysticercosis}

Unfortunately we have come to the final part of this chapter faced severe space restrictions by what we have to reduce the content of each paragraph without sacrificing the quality of this chapter.

The abdominopelvic cavity (APC) is the cavity of the human body that holds the bulk of the viscera including include the stomach, liver, gallbladder, spleen, pancreas, small intestine, kidneys, large intestine and reproductive organs, the urinary bladder, the pelvic colon, and the rectum. The APC is lined with a protective membrane termed the peritoneum. The kidneys are located in the abdominal cavity behind the peritoneum, in the retroperitoneum. The viscera are also covered, in the front, with a layer of peritoneum called the greater 
omentum. The peritoneal cavity is a potential space between the parietal peritoneum and visceral peritoneum, that is, the two membranes that separate the organs in the abdominal cavity from the abdominal wall. The peritoneal cavity is the largest serosa sac in the body and secretes approximately $50 \mathrm{ml}$ of fluid per day. This fluid acts as a lubricant and has antiinflammatory properties.

Cysticercosis of the whole APC is another preventable faeco-oral transmitted T solium infection but for didactic purposes we will divide this topic in extra-abdominal and intraabdominal cysticercosis.

\subsection{Extra-abdominal cysticercosis}

In the abdominal, wall $T$ solium cysticercosis can be found involving the anterior abdominal wall musculature [306-308] and diagnosis can be done by sonography which can reveal a well-defined cystic lesion with an eccentric hyperechoic area within it and an eccentric, echogenic, pedunculated structure is seen within the cystic area of the lesion without calcification but inflammation and hypervascularity in the surrounding muscle also can be noted or can be confirmed by histopathology. Clinical manifestations include vague abdominal discomfort, tender or painless nodules. This presentation is more commonly seen in patients presenting disseminated cysticercosis [283, 292, 293, 296-298, 300-303] rather than isolated cysticercosis. [277-282, 286-289, 294]

\subsection{Intra-Abdominal cysticercosis}

In some anecdotal cases intra-abdominal cysticercosis is presenting as abdominal pain secondary to acute abdomen and reported cases have shown psoas muscle cysticercosis mimicking appendicitis [309] and mesenteric lymph node enlargement cysticercosis and associated appendicitis. [310] In this case is postulated that the larvae, after evagination in the small intestine, penetrated the mesenteric lymphatic, burrowing through the bowel wall, hence reaching the mesenteric lymph node. The before-cited case is the second case of isolated lymph node enlargement due to cysticercus infestation reported in the medical literature.

One study made by Vianna et al., [311] shows the frequency of cutaneous, muscular and visceral forms of cysticercosis in anatomopathological examinations and necropsies in the Federal District of Sao Paulo. In 64.911 protocols of anatomopathological examinations they found that $30(0.05 \%)$ had the diagnosis of cysticercosis, $90 \%$ had cysticerci in the subcutaneous tissue, skeletal muscle or mucous membrane, $3.3 \%$ in lymph node and $6.7 \%$ in the central nervous system and two $(7.4 \%)$ patients had cysticerci in the tongue. In 1520 autopsy protocols reviewed, 25 (1.6\%) autopsies with cysticercosis were found. $96 \%$ had cysticerci in the central nervous system, $8 \%$ in the heart, $8 \%$ in the skeletal muscle and $4 \%$ in the liver, either isolated or associated with cysticerci in other viscera. A total of 1122 people were also examined and the muscular cysticercosis was found in $42.4 \%$, subcutaneous cysticercosis was present in $20.3 \%$ and the visceral cysticercosis was found in $3.4 \%$ of cases. 
In this series patient with visceral cysticercosis, the cysts were localized in the heart, pleura, kidney and ovary without clinical manifestations of importance.

\subsection{Hepatic cysticercosis}

Cysticercosis of the liver by $\mathrm{T}$ solium or other tapeworms has been reported in the animal population since long time ago, [312] and the first human being patient with hepatic cysticercosis and clinical manifestations of liver damage and not associated to disseminate cysticercosis was reported in the international medical literature in 1995. [313] Up to date only four patients with hepatic cysticercosis have been well documented.[313-316] Solitary nodular lesion remains asymptomatic while multinodular lesions may manifest as acute or chronic hepatitis. The experience of the last report highlights the need to use high resolution ultrasonography of abdomen in patients with a high index of suspicion. [314]

\subsection{Pancreatic cysticercosis}

In one of the previous chapter we mentioned that DCC is a rare form of cysticercosis caused by dissemination of the larval form of the pork tapeworm $T$. solium and fewer than 50 cases have been reported worldwide. Involvement of the pancreas and spleen is even rarer. The best of our knowledge, the first patient presenting splenic and pancreatic involvement by cysticercosis leading to pancreatitis was born and grew up at the former rural Transkei in South Africa (where we are living) and was reported in 1987 by Scholtz and Mentis [240] the second case is reported by Jain et al., [317] and their patient presented a history of headache and vomiting and was found to have DCC with pulmonary, cardiac , pancreatic, intraocular, and extradural spinal canal involvement. The third (last one) patient presented a disseminated cysticercosis involving the brain, orbit, myocardium, muscle, subcutaneous tissues, spleen and pancreas but without clinical or biochemical evidence of pancreatitis due to infection by cysticerci. [318]

\subsection{Spleen and Kidney cysticercosis}

Cysticercosis of the spleen [318,319] and the kidneys [240, 311,319] have been reported in two and three occasions respectively, always as part of a disseminate cysticercosis. Clinical manifestations secondary to the spleen or renal damage caused by T solium are uncertain up to date. The first reported patient presenting renal cysticercosis came from our region.

\subsection{Pelvic cysticercosis}

Tenia solium cysticercosis can infect ovary and one anecdotal case has been without remarkable clinical manifestation has been reported. [311]

\subsection{Peritoneal cysticercosis}

There are several types of tapeworms such as $T$ pisiformis, $T$ hydatigena, $T$ saginata, Taenia crassiceps and other parasites that can be found in the peritoneal cavity in several types of 
animals, [320-324] but we are not aware of patients with peritoneal cysticercosis caused by T solium cysticercosis up to date.

\subsection{Adrenal gland cysticercosis}

The adrenal glands (also known as suprarenal glands) are endocrine glands that sit atop the kidneys; in humans, the right adrenal gland is triangular shaped, while the left adrenal gland is semilunar shaped. On CT scan, the average measurements for the right adrenal gland were: maximum width $0.61 \mathrm{~cm}$ (S.D. 0.2), the width of the medial limb $0.28 \mathrm{~cm}$ (S.D. 0.08 ), and width of the lateral limb $0.28 \mathrm{~cm}$ (S.D. 0.06). The average measurements for the left adrenal gland were: maximum width $0.79 \mathrm{~cm}$ (S.D. 0.21 ), width of the medial limb 0.33 $\mathrm{cm}$ (S.D. 0.09), and width of the lateral limb $0.30 \mathrm{~cm}$ (S.D. 0.10), [325] typically, they are less than $4 \mathrm{~cm}$ in length and less than $1 \mathrm{~cm}$ in width.

Although variations of the blood supply to the adrenal glands are common, there are usually three arteries that supply each adrenal gland such as: the superior suprarenal artery, the middle suprarenal artery and the inferior suprarenal artery which represent three paths for cysticercosis to reach the adrenal glands. However due to the size of the adrenal glands the cysticerci cannot be accommodated there; therefore, the adrenal cistticercosis does not exist. Nevertheless, there are clinical manifestations of adrenal dysfunction related to $\mathrm{T}$ solium cysticercosis (even simulating pheocromocytoma) but secondary to NCC [326-328] when it is affecting the limbic-hypothalamic-pituitary-adrenal axis.

\section{Conclusion}

After an extensive review of the medical literature and from our database, we concluded that the uncommon clinical manifestations of cysticercosis are related to the immune status of the patient, the location and numbers or cisticercus in any organ or tissue able to accommodate cysticerci depending of its size, consistency of the tissue, and the characteristics of its blood supply.

From the before-mentioned postulate is that there will never be cysticercosis in the skin, hair, nails, bones, and or organs, tissues and membranes with dimensions less than one centimeter. Outside of this rule, the cysticerci can be viewed in any organ of the human body causing direct or indirect damage with or without clinical manifestations. So any patient from an endemic area or not presenting clinical manifestation of unknown causes deserves an investigation in search of cysticercosis.

\section{Author details}

Humberto Foyaca Sibat and Lourdes de Fátima Ibañez Valdés

Department of Neurology, Stroke Unit, Epilepsy and neurocysticercosis Clinic in Nelson Mandela Academic Hospital, Faculty of Health Sciences,

Walter Sisulu University, Mthatha, South Africa 


\section{Acknowledgement}

We wish to mention our eternal and deepest gratitude to Lorna María Foyaca García, Fátima Susana Foyaca Ibañez and Thabo Humberto Foyaca Ibañez for their delight support.

Hereby, we acknowledge financial support from the Directorate of Research Development, Walter Sisulu University in South Africa, South African Medical Research Council and NRF. The founder had no role in study design, data collection and analysis, decision to publish, or preparation of the manuscript.

\section{References}

[1] Foyaca-Sibat H, Ibañez-Valdés LdeF."Clinical trial of praziquantel and prednisone in rural patients with neurocysticercosis presenting recurrent epileptic attacks" The Internet Journal of Neurology 2002;2):41-50.

http://www.ispub.com/journal/the_internet_journal_of_neurology/volume_1_number_ 2_39/article/clinical_trial_of_praziquantel_and_prednisone_in_rural_patients_with_neu rocysticercosis_presenting_with_recurrent_epileptic_attacks.html

[2] Foyaca-Sibat H, Ibañez-Valdés LdeF."Intraventricular neurocysticercosis in HIV patients. Should be approaching surgically?" II International Congress of Neurosurgery on Internet. 2003 Conference Proceeding http://www.neuroc.sld.cu/paper/TLneurocys.htm

[3] Foyaca-Sibat H, Ibañez-Valdés LdeF "Intraventricular neurocysticercosis in HIV patients" The Internet Journal of Neurology 2003;2(1):23-31.

http://www.ispub.com/journal/the_internet_journal_of_neurology/volume_2_number_ 1_37/article/intraventricular_neurocysticercosis_in_hiv_positive_patients.html

[4] Foyaca-Sibat H, Ibañez-Valdés LdeF."Pseudoseizures and Epilepsy in neurocysticercosis" Electron J Biomed 2003;2(2):20-29.

http://www.uninet.edu/reb/2003/n2/2foyaca.html

[5] Foyaca-Sibat H, Ibañez-Valdés LdeF "Neurocysticercosis in HIV-positive patients" The Internet Journal of Infectious Diseases 2003:2(2):15-23.

http://www.ispub.com/ostia/index.php?xmlFilePath=journals/ijn/current.xml

[6] Ibañez-Valdés LdeF, Foyaca-Sibat H. Refractory epilepsy in neurocysticercosis. The Internet Journal of Neurology 2006;5(2):34-41.

http://www.ispub.com/journal/the_internet_journal_of_neurology/volume_5_number_ 2_19/article/refractory_epilepsy_in_neurocysticercosis.html

[7] Foyaca-Sibat H. Ibañez-Valdés LdeF. Insular Neurocysticercosis: Our Finding and Review of the Medical Literature. The Internet Journal of Neurology 2006 vol 5 Number 2.

http://www.ispub.com/journal/the_internet_journal_of_neurology/volume_5_number_ 2_19/article/insular_neurocysticercosis_our_findings_and_review_of_the_medical_liter ature.html 
[8] Carabin H, Krecek RC, Cowan LD, Michael L, Foyaca-Sibat H, Nash T, Willingham AL "Estimation of the monetary burden of Taenia solium cysticercosis in the Eastern Cape, South Africa". Trop. Med. Int. Health.( ISSN: 1360-2276). 2006;11: 906-916.

[9] Foyaca-Sibat H, Ibañez-Valdés LdeF : Occipital Lobe Syndrome Due To Giant Intraparenchymal Neurocysticercosis . The Internet Journal of Neurology. 2006 Volume 5 Number 2.

http://www.ispub.com/journal/the_internet_journal_of_neurology/volume_5_number_ 2_19/article/occipital_lobe_syndrome_due_to_giant_intraparenchymal_neurocysticerco sis.html

[10] Foyaca-Sibat H, Ibañez-Valdés LdeF: "Generalized Cysticercosis With Cardiac Involvement". The Internet Journal of Neurology.( ISSN: 1531-295X). 2007;7(2):6-11 http://www.ispub.com/journal/the_internet_journal_of_neurology/volume_7_number_ 2_5/article/generalized_cysticercosis_with_cardiac_involvement.html

[11] Foyaca-Sibat H, Ibañez-Valdés LdeF: “Co-morbidity of Spinal Cord Neurocysticercosis And Tuberculosis In A HIV-Positive Patient". The Internet Journal of Neurology. ( ISSN: 1531-295X). 2007;7(3):5-10

http://www.ispub.com/journal/the_internet_journal_of_neurology/volume_7_number_

2_5/article/comorbidity_of_spinal_cord_neurocysticercosis_and_tuberculosis_in_a_hiv_ positive_patient.html

[12] Foyaca-Sibat H Cowan LD, Carabin H, Serrano-Ocaña G, , Krecek RC, Willingham A. "Accuracy of serological exam for the diagnosis of neurocysticercosis in outpatients with epilepsy, Eastern Cape Province, South Africa" PLOS Negleted Trop.Dis.Dec.2009;3(3):1-7.

[13] Foyaca-Sibat H, Ibañez-Valdés LdeF \& J. Moré-Rodríguez: Parasitic Zoonoses Of The Brain: Another Challenger?. The Internet Journal of Neurology. 2010 Volume 12 Number 2

http://www.ispub.com/journal/the_internet_journal_of_neurology/volume_12_number _2_4/article/parasitic-zoonoses-of-the-brain-another-challenger.html

[14] Humberto Foyaca-Sibat and Lourdes de Fátima Ibañez-Valdés (2011). Treatment of Epilepsy Secondary to Neurocysticercosis, Novel Treatment of Epilepsy, Humberto Foyaca-Sibat (Ed.), ISBN: 978-953-307-667-6, InTech, Rijeka

[15] Humberto Foyaca-Sibat and Lourdes de Fátima Ibañez Valdés (2011). Clinical Features of Epilepsy Secondary to Neurocysticercosis at the Insular Lobe, Novel Aspects on Epilepsy, Humberto Foyaca-Sibat (Ed.), ISBN: 978-953-307-678-2, InTech, Rijeka

[16] Humberto Foyaca-Sibat (2011). Epilepsy Secondary to Parasitic Zoonoses of the Brain, Novel Aspects on Epilepsy, Humberto Foyaca-Sibat (Ed.), ISBN: 978-953-307-678-2, InTech, Rijeka

[17] Takayanagui OM, Jardim E. Clinical aspects of nerocysticercosis: analysis of 500 cases. Arq Neuropsiquiatr 1983; 41(1):50-63.

[18] Takayanagui OM. Neurocysticercosis: I.Clinical and laboratory course of 151 cases. Arq Neuropsiquiatr 1990; 48(1):1-10. 
[19] Takayanagui OM, Leite JP. Neurocysticercosis. Rev Soc Bras Med Trop 2001;34(3):283290.

[20] Sarti E. La taeniasis y cisticercosis en México (revisión bibliográfica). Salud Pública Mex 1986; 28:556-563.

[21] McComick G, Zec Chi-S, Heiden J. Cysticercosis Cerebri. Review of 127 cases. Arch Neurol 1982; 39:534-539.

[22] Lopez-Hernández A, Garaizar C. Childhood Cerebral Cysticercosis: clinical features and computed tomographic findings in 98 Mexican children. Can J Neurol SC 1982;9:401-407.

[23] Kalra V, Paul VK, Marwah RK, Kichhar Gs, Bhargava S. Neurocysticercosis in childhood. Trans R Soc Trop Med Hyg 1987;81(3):371-373.

[24] Scharf D. Neurocysticercosis. Two hundred thirty-eight cases from a California Hospital. Arch Neurol 1988; 45:777-780.

[25] Sotelo J, Penagos P, Escobedo F, Del Brutto OH: Short course of albendazole therapy for neurocysticercosis. Arch Neurol 45:1130-1133, 1988.

[26] Villa AM, Monteverde DA, Rodríguez W, Boero A, Sica RE. Neurocysticercosis in a hospital of the city of Buenos Aires: study of 11 cases. Arq Neuropsiquiatr 1993;51(3):336336.

[27] Pitella JEH. Neuro schistosomiasis. Brain Pathol 1997;7:649-662.

[28] Singh G. Neurocystycercosis in South-Central America and the Indian subcontinent. A comparative evaluation. Arq Neuropsiquatr 1997; 55(3A):349-356.

[29] Singhi P, Ray M, Singhi S, Khandelwal N. Clinical spectrum of 500 children with neurocysticercosis and response to albendazole therapy. J Child Neurol 2000;15(4):207213.

[30] Del Bruto OH, Santibáñez R, Rubio CA, Aguirre R, Diez E, Alarcón TA. Epilepsy due to neurocysticercosis: analysis of 203 patients. Neurology 1992; 42:389-392.

[31] Del Brutto OH. Neurocysticercosis in children: clinical and radiological analysis and prognostic factor in 54 patients. Rev Neurol 1997; 25(147):1681-1484.

[32] Del Brutto OH. Neurocysticercosis. Rev Neurol 1999; 29(5):4456-4466.

[33] Del Bruto OH, Rajshekhar V, White AC Jr, Tsang VC, et al. Proposed diagnostic criteria for Neurocysticercosis. Neurology 2001; 57(2):177-183.

[34] Rousseau MC, Guillotel B, Delmont J. Neurocysticercosis in the South-East of France 1988-1998. Presse Med 1999;28(39):2141-2144.

[35] Sanchez AL, Ljungstrom I, Medina MT. Diagnosis of human neurocysticercosis in endemic countries: clinical study in Honduras. Parasitol Int 1999;48(1):81-89.

[36] Turkulov V, madle-Samardzija N, Canak G, Vukadinov J, Aleksic-Dordevic M. Clinical and diagnostic approaches to neurocysticercosis. Med Pregl 2001; 54(7-8):353-356.

[37] Varma A, Gaur KJ. The clinical spectrum of Neurocysticercosis in the Uttraranchal region.Assoc Physicians India 2002;50:1398-1400.

[38] Carpio A. Neurocysticercosis: an update. Lancet Infect Dis 2002;2:751-62.

[39] Carpio A, Hauser WA. Prognosis for seizure recurrence in patients with newly diagnosed neurocysticercosis. Neurology 2002;59:1730-1734. 
[40] García HH, del Brutto OH. Taenia solium cysticercosis. Infect Dis Clin North Am 2000; 14(1):97-119.

[41] García HH, Evans CA, Nash TE, Takayanagui OM, White AC jret al., Current Consensus Guidelines for Treatment of Neurocysticercosis. Clin Microbiol Rev 2002; 15(4)747-756.

[42] White AC Jr. Neurocysticercosis: a major cause of neurological disease worldwide. Clin Infect Dis 1997;24:101-106.

[43] White AC Jr. Neurocysticercosis: updates on epidemiology, pathogenesis, diagnosis and management. Ann Rev Med 2000;51:187-206.

[44] Uddin J, Garcia HH, Gilman RH, Gonzalez AE, Friedland JS. Monocyte-astrocyte networks and the regulation of chemokine secretion in neurocysticercosis. J Immunol. 2005 Sep 1;175(5):3273-3281.

[45] Figueroa JJ, Davis LE, Magalhaes A. Extraparenchymal neurocysticercosis in Albuquerque, New México. J Neuroimaging. 2011;21(1):38-43.

[46] Wallin M, Kurtzke J. Neurocysticercosis in the United States: review of an important emerging infection. Neurology 2004; 63: 1559-1564.

[47] De Giorgio CM, Medina MT, Duron R, Zee C,. Escueta SP: Neurocysticercosis. Epilepsy Curr: 2004;4(3):107-111.

[48] Bhigjee AI, Rosemberg S Optimizing therapy of seizures in patients with HIV and cysticercosis. NEUROLOGY 2006;67(Suppl 4):S19-S22.

[49] Devinsky O. Patients with refractory seizures. N Engl J Med 1999; 340: 1.565-1.570.

[50] Ramirez-Bermudez J, Higuera J, Sosa AL,et al. Is dementia reversible in patients with neurocysticercosis? J Neurol Neurosurg Psychiatry 2005; 76:1164-1166.

[51] García HH, Del Brutto OH,The Cysticercosis Working Group in Perú. Heavy nonencephalitic cerebral cysticercosis in tapeworm carriers. Neurology 1999; 53(7):1582.

[52] Colli BO, Martelli N, Assirati JA Jr, et al. Surgical treatment of cysticercosis of the central nervous system. Neurosurgery Quarterly 1995:5;34-35.

[53] Umredkar A, Singla N, Mohindra S, Bal A, Gupta SK. Giant intraparenchymal neurocysticercosis: Report of surgical aspects two cases. Neurol India 2009;57:800-802.

[54] Agarwal PP, Gaikwad SB, Garg A, Gupta V, Mishra NK, Mehta VS. Giant intraparenchymal neurocysticercosis: Unusual MRI findings. Neurol India 2004;52:259260.

[55] Prachi P. Agarwal, Shailesh B. Gaikwad, Ajay Garg, Vipul Gupta, N. K. Mishra, V. S. Mehta. Giant intraparenchymal neurocysticercosis: Unusual MRI Findings.Neurology India 2004;52(2):259-260.

[56] Joubert J, Van As AD. Rapid and complete resolution of giant cysticercal cysts after administration of praziquantel. A report of 4 cases. S Afr Med J. 1990;77(3):154-157.

[57] Berman JD, Beaver PC, Cheever AW, Quindlen EA. Cysticercus of 60-milliliter volume in human brain. Am J Trop Med Hyg 1981;30:616-619.

[58] Castellanos F, Montes I, Porras LF, Peragallo E, Ampuero J, Rueda R. Quistes subarachnoideos gigantes por neurocisticercosis: a propósito de dos casos observados en un área rural de Extremadura. Rev Neurol 2000;30:433-435. 
[59] Ramesh VG, Parthiban A. Giant parenchymal cysticercosis with unusual imaging features. J Clin Neurosci 2008;15:1404-1406.

[60] Proaño JV, Madrazo I, Avelar F, López-Félix B, Díaz G, Grijalva I. Medical treatment for neurocysticercosis characterized by giant subarachnoid cysts. $N$ Engl J Med 2001;345:879-85.

[61] Agarwal PP, Gaikwad SB, Garg A, Gupta V, Mishra NK, Mehta VS. Giant intraparenchymal neurocysticercosis: unusual MRI findings. Neurol India. 2004 Jun;52(2):259-260.

[62] Umredkar A, Singla N, Mohindra S, Bal A, Gupta SK. Giant intraparenchymal neurocysticercosis: Report of surgical aspects two cases. Neurology India 2009;57(6):800-802.

[63] Takeshita I, Li HZ, Imamoto N, Cao YP, Gou CF, Liu DQ, Piao HZ, Fukui M.Unusual manifestation of cerebral cysticercosis. Fukuoka Igaku Zasshi. 1994;85(1):29-34.

[64] Amaral L, Maschietto M, Maschietto R, Cury R, Ferreira NF, Mendonça R, et al. Unusual manifestations of neurocysticercosis in MR imaging : analysis of 172 cases. Arq Neuropsiquiatr. 2003;61:533-541.

[65] Rocca U, Rosell A, Alvarez C. Surgical options in neurocysticercosis therapy. Neurosurg Q. 2005;15:5-13.

[66] Bickerstaff Er, Small JM, Woolf AL. Cysticercosis of the posterior fossa. Brain 1956;79:622-634.

[67] Kla O. The clinical aspects and surgical treatment of racemose cysticercosis of the posterior cranial fossa. Vopr Neirokhir. 1961;25:30-34.

[68] Lopes PG.Surgical treatment of cysticercosis of the posterior cranial fossa. Arq Neuropsiquiatr. 1971;29(1):76-92.

[69] Filizzolo F, Nastasi G, Morello A. Cysticercosis of the posterior cranial fossa. Acta Neurol (Napoli). 1972;27(6):632-638.

[70] Lushchenko AI. Diagnostic importance of laboratory and serological analysis of blood and cerebrospinal fluid in cysticercosis of the posterior cranial fossa. Lab Delo. 1975;(7):409-411.

[71] de Morais-Rêgo SF, Latuf NL. Cysticercosis of the fourth ventricle simulating a posterior fossa neoplasm in cerebral scintillography. Report of a case. Arq Neuropsiquiatr. 1978 Dec;36(4):371-374.

[72] Keane JR.Cysticercosis: unusual neuro-ophthalmologic signs. J Clin Neuroophthalmol. 1993 Sep;13(3):194-199.

[73] Kim JH, Suh SI, Kim JH, Kwon TH, Chung HS. Giant neurocysticercosis cyst in the cerebellar hemisphere. Neurol Med Chir (Tokyo) 2006; 46:412-4.Neurol India. 2004 Jun;52(2):259-60.

[74] Cheepsattayakorn R, Tantachamroon T. Cysticercosis in the posterior cranial fossa. J Med Assoc Thai 1994;77:544-548.

[75] Chang JH, Chang JW, Park YG, Kim TS.Cysticercosis of cerebellopontine cistern: differential diagnosis using MRI. Acta Neurochir (Wien). 2004 Apr;146(4):325-328. 
[76] Sang-Wook K, Moon-Kyu K, Sae-Moon O, Se-Hyuck P. Racemose Cysticercosis in the Cerebellar Hemisphere. J Korean Neurosurg Soc. 2010;48(1):59-61.

[77] Zhu L, Shi Y, Pan X, Mo L, Weng X. Successful treatment of isolated cerebellar cysticercosis with albendazole. Chin Med J (Engl) 2003;116:637-638.

[78] Kim JH, Suh SI, Kim JH, Kwon TH, Chung HS. Giant neurocysticercosis cyst in the cerebellar hemisphere. Neurol Med Chir (Tokyo) 2006;46:412-414.

[79] Lalla RS, IyerVV, Asgaonkar DS. Neurocysticercosis as Anterior Inferior Cerebellar Artery syndrome. Bombay Hospital Journal. 2011;53(3): 643-645.

[80] Zee CS, et al. MRI of intraventricular cysticercosis: Surgical implications. J Comput Assist Tomogr 1993;17(6):932-939.

[81] Govindappa SS, et al. Improved detection of intraventricular cysticercal cyst with the use of three-dimensional constructive interference in steady state MR sequences. Am J Neuroradiol 2000;21(4):679- 684.

[82] Sánchez L, Abad L, Lozano E, Maldonado G. Neurocisticercosis intraventricular. Presentación de un caso localizado en el tercer ventriculo. Radiologia. 2002;44:309-313.

[83] Earnest MP, Reller LB, Filley CM, Grek AJ. Neurocysticercosis in the United States: 35 cases and review. Rev Infect Dis. 1987;9(5):961-979.

[84] Kelesidis T, Tsiodras S. Extraparenchymal neurocysticercosis in the United States: a case report. Journal of Medical Case Reports 2011;5:359 .

[85] Aguilar-Amat M, Martínez-Sánchez J, Medina P, et al. Síndrome de Bruns causado por neurocisticercosis intraventricular. Med Clin (Barc). 2011;137(1):45-46.

[86] Carod-Artal FJ, et al. Neurocisticercosis intraparenquimatosa diseminada. Rev Neurol 2000;30(5):498-499.

[87] Cuetter AC, et al. Neurocisticercosis: Focus of intraventricular disease. Clinical Infectious Disease 1997;24:157-164.

[88] Kramer J, et al. Transaqueductal migration of a neurocysticercus cyst. J Neurosurgery 1992;77:956-958.

[89] Neal JH. An endoscopic approach to cysticercosis cysts of the posterior third ventricle. Neurosurgery 1995;36(5):1040-1043.

[90] Madrazo I, Proaño J. Tratamiento quirúrgico de la neurocisticercosis. En: Arriagada C, Nogales-Gaete J, Apta W, eds. Neurocisticercosis. Santiago: ARRYNOG 1997; 299-321.

[91] García HH, Gonzalez AE, Evans CA, Gilman RH; Cysticercosis Working Group in Peru. Taenia solium cysticercosis. Lancet. 2003; 362: 547-556.

[92] Proaño JV, Madrazo I, García L, García-Torres E, Correa D. Albendazole and praziquantel treatment in neurocysticercosis of the fourth ventricle. J Neurosurg 1997; 87: 29-33.

[93] Kelley R, Duong D, Locke G. Characteristics of Ventricular Shunt Malfunctions among patients with Neurocysticercosis. Neurosurgery 2002; 50:757-762.

[94] Nogales-Gaete J, Arriagada RC, Rodrigo SR. Tratamiento de la neurocisticercosis: Revisión crítica. Rev Méd Chile 2006; 134: 789-796.

[95] Ramírez-Ceballos JA, Marquéz RMC.Tratamiento endoscópico de la neurocisticercosis intraventricular. Rev Neurocir 2007;9(4):107-113. 
[96] Govindappa SS, et al. Improved detection of intraventricular cysticercal cyst with the use of three-dimensional constructive interference in steady state MR sequences. Am J Neuroradiol 2000;21(4):679- 684.

[97] Sánchez L, Abad L, Lozano E, Maldonado G. Neurocisticercosis intraventricular. Presentación de un caso localizado en el tercer ventriculo. Radiologia. 2002;44:309-313.

[98] Gallonel L, Bedushi A, D'Andrea F. Clinical aspects and therapeutic possibilities in cysticercosis of the fourth ventricle. Riv Patol Nerv Ment. 1957;78(3):1183-1186.

[99] Patharangkura P, Jariya P, Tandhavadhana. Cysticercus racemosus in the fourth ventricle: report of two cases. Southeast Asian J Trop Med Public Health. 1980;11(4):532534.

[100] Palmer J, Poulgrain P. Cysticercosis of the fourth ventricle: a report of two cases. Aust N Z J Surg. 1980 Feb;50(1):60-63.

[101] Elliott EM, Fried RA. Cerebral cysticercosis of the fourth ventricle: a problem in primary care diagnosis. J Fam Pract. 1984;19(4):553-557.

[102] Gupta RK, Jain VK, Kumar S, Gupta S, Haque I, Gujral RB. Unusual MRI appearances of cysticercus within the fourth ventricle. Neuroradiology. 1993;35(6):457-458.

[103] Flisser A, Madrazo I. Evagination of Taenia solium in the fourth ventricle. N Engl J Med. 1996;335(10):753-754.

[104] Govindappa SS, Narayanan JP, Krishnamoorthy VM, Shastry CH, Balasubramaniam A, Krishna SS. Improved detection of intraventricular cysticercal cysts with the use of three-dimensional constructive interference in steady state MR sequences. AJNR Am J Neuroradiol. 2000;21(4):679-684.

[105] Savindra TL et al. Neurocysticercosis in Asia. The Internet Journal of Infectious Diseases 2002:1(2):21-23.

[106] Singh S, Gibikote SV, Shyamkumar NK. Isolated fourth ventricular cysticercus cyst: MR imaging in 4 cases with short literature review. Neurol India. 2003;51(3):394-396.

[107] Hortobágyi T, Alhakim A, Biedrzycki O, Djurovic V, Rawal J, Al-Sarraj S. Cysticercosis of the fourth ventricle causing sudden death: a case report and review of the literature. Pathol Oncol Res. 2009;15(1):143-146.

[108] Prashantha DK, Netravathi M, Ravishankar S, Panda S, Pal PK. Reversible parkinsonism following ventriculoperitoneal shunt in a patient with obstructive hydrocephalus secondary to intraventricular neurocysticercosis. Clin Neurol Neurosurg. 2008;110(7):718-721.

[109] Das A, Kesavadas C, Radhakrishnan VV, Nair NS. Teaching NeuroImages: Bruns syndrome caused by intraventricular neurocysticercosis. Neurology. 2009 Aug 18;73(7):e34.

[110] Roongpiboonsopit D, Shuangshoti S, Phanthumchinda K, Bhidayasiri R. Positional vomiting as the initial manifestation of Bruns syndrome due to cysticercosis in the fourth ventricle: a symptom reminiscent of an old disease. Eur Neurol. 2012;67(3):184185. 
[111] Hanak BW, Walcott BP, Codd PJ, Jones PS, Nahed BV, Butler WE, Asaad WF. Fourth ventricular neurocystercercosis presenting with acute hydrocephalus. J Clin Neurosci. 2011;18(6):867-869.

[112] Singh S, Gibikote SV, Shyamkumar NK. Isolated fourth ventricular cysticercus cyst: MR imaging in 4 cases with short literature review. Neurol India. 2003;51(3):394-396.

[113] Costa CU, von Einsiedel HG, Disko R, Berthele A. Multicystic tumor in the fourth ventricle: consider neurocysticercosis. J Neurol. 2006;253(8):1092-1093.

[114] Loyo M, Kleriga E, Estañol B. Fourth ventricular cysticercosis. Neurosurgery. 1980;7(5):456-458.

[115] Allcut DA, Coulthard A. Neurocysticercosis: regression of a fourth ventricular cyst with praziquantel. J Neurol Neurosurg Psychiatry. 1991;54(5):461-462.

[116] Proaño JV, Madrazo I, García L, García-Torres E, Correa D.Albendazole and praziquantel treatment in neurocysticercosis of the fourth ventricle. J Neurosurg. 1997;87(1):29-33.

[117] Anandh B, Mohanty A, Sampath S, Praharaj SS, Kolluri S. Endoscopic approach to intraventricular cysticercal lesions. Minim Invasive Neurosurg. 2001;44(4):194-196.

[118] Citow JS, Johnson JP, McBride DQ, Ammirati M. Imaging features and surgery-related outcomes in intraventricular neurocysticercosis. Neurosurg Focus. 2002 Jun 15;12(6):e6.

[119] Zymberg ST, Paiva Neto MA, Gorgulho AA, Cavalheiro S. Endoscopic approach to fourth ventricle cysticercosis. Arq Neuropsiquiatr. 2003;61(2A):204-207.

[120] Psarros TG, Coimbra C. Endoscopic third ventriculostomy for patients with hydrocephalus and fourth ventricular cysticercosis: a review of five cases. Minim Invasive Neurosurg. 2004;47(6):346-349.

[121] Lapergue B, Hosseini H, Liance M, Rosso C, Decq P. Hydrocephalus and racemose cysticercosis: surgical alternative by endoscopic third ventriculostomy. Neurochirurgie. 2005;51(5):481-488.

[122] Husain M, Rastogi M, Jha DK, Husain N, Gupta RK.Endoscopic transaqueductal removal of fourth ventricular neurocysticercosis with an angiographic catheter. Neurosurgery. 2007;60(Suppl 2):249-253.

[123] Husain M, Jha DK, Rastogi M, Husain N, Gupta RK. Neuro-endoscopic management of intraventricular neurocysticercosis (NCC). Acta Neurochir (Wien). 2007;149(4):341346.

[124] Suri A, Goel RK, Ahmad FU, Vellimana AK, Sharma BS, Mahapatra AK. Transventricular, transaqueductal scope-in-scope endoscopic excision of fourth ventricular neurocysticercosis: a series of 13 cases and a review. J Neurosurg Pediatr. 2008;1(1):35-39.

[125] Cappabianca P, Cinalli G, Gangemi M, Brunori A, Cavallo LM, de Divitiis E, Decq P, et.al. Application of neuroendoscopy to intraventricular lesions. Neurosurgery. 2008; 62(2):575-597.

[126] Hanak BW, Walcott BP, Codd PJ, Jones PS, Nahed BV, Butler WE, Asaad WF. Fourth ventricular neurocystercercosis presenting with acute hydrocephalus. J Clin Neurosci. 2011;18(6):867-869. 
[127] Wallin M, Kurtzke J. Neurocysticercosis in the United States: review of an important emerging infection. Neurology 2004; 63: 1559-1564.

[128] Del Brutto O, Sotelo J. Neurocysticercosis Up date. Rev. Inf. Dis.1988;10(6):1075-1087.

[129] Del Bruto OH, Rajshekhar V, White AC Jr, Tsang VC, et al. Proposed diagnostic criteria for Neurocysticercosis. Neurology 2001; 57(2):177-183.

[130] Del Brutto O, Sotelo J. Albendazole therapy for subarachnoid and ventricular cysticerciosis. J Neurosurgery 1990; 62: 816-817.

[131] Proaño JV, Madrazo I, Avelar F, López-Félix B, Díaz G, Grijalva I. Medical treatment for neurocysticercosis characterized by giant subarachnoid cysts. $N$ Engl J Med. 2001;345:879-885.

[132] García HH, Evans CA, Nash TE, Takayanagui OM, White AC jret al., Current Consensus Guidelines for Treatment of Neurocysticercosis. Clin Microbiol Rev 2002; 15(4)747-756.

[133] Cruz-Ultreras I, Cruz M. Tratamiento médico de la neurocisticercosis. En: Arriagada C, Nogales-Gaete J, Apta W, eds. Neurocisticercosis. Santiago: ARRYNOG 1997; 287-98.

[134] Hatano S. Experience from a multicentre stroke registry: a preliminary report Bull World Health Organ. 1976;54:541-553.

[135] Portenog RK, Abissi CJ, Lipton RB. Headache in acute cerebrovascular disease. Stroke 1985;15:1009-1012.

[136] Chodosh EH, Foulkes MA, Kase CS. Silent stroke in NINCDS stroke data bank. Neurology 1988;38: 1674-1679.

[137] Cárdenas F, Quiroz H, Plancarte A. Taenia solium ocular cysticercosis: findings in 30 cases. Ann OphthalmoI 1992; 24:25-28.

[138] Alarcon F, Vanormelingen K, Moncayo J, Vinan I. Cerebral cysticercosis as a risk factor for stroke in young and middle-age people. Stroke 1992;23:1563-1565.

[139] Dantas FL. Fagundes-Pereyra WJ, De Souza CT, Vega MG, De Souza AA. Intramedullary cysticercosis: case report Arq Neuropsiquiatr 1999;57(2A):301-305.

[140] Musumdar D, Nadkarni T, Desai K, Dindorkar K, Goel A. Thoracic intramedullary cysticercosis. Neurol Med Chir (Tokyo)2002; 42 :575-579.

[141] Gallani NR, Zambelli HJ, Roth-Vargas AA, Limoli Júnior C.Spinal cord cysticercosis: report of 2 cases, review of the literature, and comments on its pathogeny. Arq Neuropsiquiatr. 1992 Sep;50(3):343-350.

[142] Mohanty A, Venkatrama SK, Das S. Spinal intramedullary cysticercosis. Neurosurgery. 1997;40(1):82-87.

[143] Chang GY, Keane JR. Visual loss in cysticercosis: analysis of 23 patients. Neurology. 2001;57:545-548.

[144] Kishore LT, Gayatri K, Naidu MR, Mateen MA, Dinakar I, Ratnakar KS. Intramedullary spinal cord cysticercosis-a case report and literature review. Indian J Pathol Microbiol. 1991;34:219-221.

[145] Isidro-Llorens A, Dachs F, Vidal J, Sarrias M. Spinal cysticercosis. Case report and review. Paraplegia. 1993;31:128-130. 
[146] Parmar H, Shah J, Patwardhan V. et al. MR imaging in intramedullary cysticercosis. Neuroradiology. 2001;43(11):961-967.

[147] David J. Neurocysticercosis. “Dr. House Series" .Tuesday, February 22, 2011.(Last review on September 22, 2011) Full article is free available at the URL: http://mentiraomedicina.blogspot.com/2011/02/neurocisticercosis.html

[148] Amaya MA, Roa JL. Neurocisticercosis raquídea: Reporte de caso. Rev Colomb Radiol. 2011;22(1):3134-3137.

[149] Mathuriya SN, Khosla VK, Vasishta RK et al. Intramedullary cysticercosis: MRI diagnosis. Neurol India. 2001;49(1):71-74.

[150] Ahmad FU, Sharma BS. Treatment of intramedullary spinal cysticercosis: report of 2 cases and review of literature. Surg Neurol. 2007;67(1):74-77.

[151] Agrawal R, Chauhan SP, Misra V. et al. Focal spinal intramedullary cysticercosis. Acta Biomed. 2008;79(1):39-41.

[152] Leite CC, Jinkins JR, Escobar BE, et al. MR imaging of intramedullary and intraduralextra medullary spinal cysticercosis. AJR 1997;169:1713-1717.

[153] Tacconi L, Arulampalam T, Johnston FG. et al. Intramedullary spinal cord abscess: case report. Neurosurgery. 1995;37(4):817-819.

[154] Clifton AG, Stevens JM, Kapoor R. et al. Spinal cord sarcoidosis with intramedullary cyst formation. Br J Radiol. 1990;63(754):805-808.

[155] Lamejjati M, Aniba K, Haddi M. et al. Spinal Intramedullary arachnoid cyst in children. Pediatr Neurosurg. 2008;44(3):243-246.

[156] Iwahashi H, Kawai S, Watabe Y. et al. Spinal Intramedullary ependymal cyst: a case report. Surg Neurol. 1999;52(4):357-361.

[157] Riviérez M, Buisson G, Kujas M. et al. Intramedullary neurenteric cyst without any associated malformation. One case evaluated by RMI and electron microscopic study. Acta Neurochir. 1997;139(9):887-890.

[158] Rahalkar MD, Shetty DD, Kelkar AB, et al. The many faces of cysticercosis. Clin Radiol. 2000;55:668-674.

[159] Thurnher MM, Cartes-Zumelzu F, Mueller-Mang C, et al. Demyelinating and infectious diseases of the spinal cord. Neuroimaging Clin N Am. 2007;17:37-55.

[160] Colli B, Morales M, Carlotti C, Rubens H, Assirati J. Spinal cord cysticercosis: neurosurgical aspects. Neurosurg Focus (e-journal) 2002; 12 (6): available at the URL http://www.medscape.com/viewpublication/65_toc?vol=12 \& iss=6. (Last review on August 09, 2012)

[161] Villanueva M, Alcocer JL, Martinez J, Horna A. Cisticercosis intramedular. Reporte de un caso. Arch Neurocien 2004;9(2):110-113.

[162] Ichiro A. Tetsuji F, Hitoshi M, Hideo M, Masakuni K. Intramedullary spinal cysticercosis. Neurology 1979; 29: 1531-1534.

[163] Alsina GA, Johnson JP, Mc Bride DQ, et al. Spinal neurocysticercosis. Neurosurg Focus 2002: 12(6):e8.

[164] Izci Y, Moftakhar R, Salamat MS, Baskaya MK.Spinal intramedullary cysticercosis of the conus medullaris.WMJ 2008;107(1):37-39. 
[165] Mathuriya SN, Khosla VK, Vasishta RK, Tewari MK, Pathak A, Prabhakar S.Intramedullary cysticercosis : MRI diagnosis. Neurol India. 2001;49(1):71-74.

[166] Vij M, Jaiswal S, Jaiswal AK, Behari S.Coexisting intramedullary schwannoma with intramedullary cysticercus: report of an unusual collision. Indian J Pathol Microbiol. 2011;54(4):866-867.

[167] Wadia N, Desai S, Bhatt M: Disseminated cysticercosis. New observations, including CT scan findings and experience with treatment by praziquantel. Brain 1988, 111:597614.

[168] Bhalla A, Sood A, Sachdev A, Varma V. Disseminated cysticercosis: a case report and review of the literature Medical Case Reports 2008; 2:137-140. Full article is available at the URL: http://www.jmedicalcasereports.com/content/2/1/137 (Last access on August 10, 2012)

[169] Flisser A. Cisticercosis subcutáneo. Ciencias, UNAM 2011. Available at the URL: http://hydra.fciencias.unam.mx:8080/xmlui/handle/123456789/62343?show=full (last accessed on August 11, 2012)

[170] Patel R, Jha S, Yadav RK.Pleomorphism of the clinical manifestations of neurocysticercosis. Trans R Soc Trop Med Hyg. 2006;100(2):134-141.

[171] Sawhney IM, Singh G, Lekhra OP, Mathuriya SN, Parihar PS, Prabhakar S. Uncommon presentations of neurocysticercosis. J Neurol Sci. 1998;154(1):94-100.

[172] Kahn P. Cysticercosis of the central nervous system with amyotrophic lateral sclerosis: case report and review of the literature. J Neurol Neurosurg Psychiatry. 1972;35(1):8187.

[173] Revuelta Gutierrez R, Soto-Hernández JL, Suastegui-Roman R, Ramos-Peek J. Transient hemifacial spasm associated with subarachnoid brainstem cysticercosis: a case report. Neurosurg Rev.1998;21(2-3):167-170.

[174] Kim JS, Jeong SM, Moon SY, Park SH. Third cranial nerve palsy from midbrain neurocysticercosis: repeated exacerbation on tapering corticosteroids. J Neuroophthalmol. 2004 Sep;24(3):217-220.

[175] Lath R, Rajshekhar V. Solitary cysticercus granuloma of the brainstem. Report of four cases. J Neurosurg. 1998;89(6):1047-1051.

[176] Singh NN, Verma R, Pankaj BK, Misra S. Neurocysticercosis presenting as Weber's syndrome. Neurol India. 2003;51(4):551-552.

[177] Chotmongkol V, Sawanyawisuth K, Limpawattana P, Phuphatham A, Chotmongkol R, Intapan PM. Superior divisional oculomotor nerve palsy caused by midbrain neurocysticercosis. Parasitol Int. 2006;55(3):223-225.

[178] Ranjith MP, Divya R, Sahni A. Isolated one and a half syndrome: An atypical presentation of neurocysticercosis. Indian J Med Sci [serial online] 2009 [cited 2012 Aug 13];63:119-120. Available from:

http://www.indianjmedsci.org/text.asp?2009/63/3/119/49291

[179] Song TJ, Suh SH, Cho H, Lee KY.Claude's syndrome associated with neurocysticercosis. Yonsei Med J. 2010;51(6):978-979. 
[180] Naphade PU, Singh MK, Garg RK, Rai D. Bilateral ptosis: an atypical presentation of neurocysticercosis. BMJ Case Reports.2012; doi:10.1136/bcr-2012-006195 http://casereports.bmj.com/content/2012/bcr-2012-006195.abstract

[181] Keane JR. The Pretectal Syndrome: 206 Patients. Neurol 1990;40:684-690

[182] Garg RK, Karak B. Neurocysticercosis presenting as midbrain syndrome. J Assoc Physicians India. 2000;48(5):533-535.

[183] Ranjith MP, Divya R, Sahni A.Isolated third cranial nerve palsy: a rare presentation of neurocysticercosis. Ir J Med Sci. 2011;180(4):905-907.

[184] Singhi P, Mahajan V, Khandelwal NK. Sudden-onset ptosis caused by midbrain neurocysticercosis in 2 children. J Child Neurol. 2008 Mar;23(3):334-337.

[185] Bolaños I, Lozano D, Cantú C. Internuclear ophthalmoplegia: causes and long-term follow-up in 65 patients. Acta Neurol Scand. 2004;110(3):161-165.

[186] Foyaca-Sibat H, Ibanez-Valdes LdeF.One-and-a half syndrome. Clinical Classification. / Electron J Biomed 2004;3:15-21. http://biomed.uninet.edu/2004/n3/foyaca.html

[187] Arruda WO, Ramina R, Pedrozo AA, et al. Brainstem cysticercosis simulating cystic tumor lesion. A case report. Arq Neuropsiquiatr 1994;52:431- 434.

[188] Bhatia R, Desai S, Garg A, Padma MV, Prasad K, Tripathi M. Isolated facial myokymia as a presenting feature of pontine neurocysticercosis. Mov Disord. 2008;23(1):135-137.

[189] Garg RK. Wallenberg's lateral medullary syndrome: a new non-vascular cause. J Assoc Physicians India. 1999;47(11):1110-1111.

[190] Aguiar PH, Miura FK, Napoli PR, Sendenski M, Rotta JM, Cescato VN, Teixeira MJ, Marino Junior R. Unusual cause for bilateral trigeminal neuralgia: unilateral racemous cysticercus of cerebellopontine angle. Case report. Arq Neuropsiquiatr. 2000;58(4):11381141.

[191] Nadkarni T, Kansal R, Goel A. Right cerebellar peduncle neurocysticercosis presenting with bradycardia. Acta Neurochir (Wien). 2010;152(4):731-732.

[192] Damasio A, Damasio H, Tranel D.Persistence of Feelings and Sentience after Bilateral Damage of the Insula. Cereb. Cortex (2012) doi: 10.1093/cercor/bhs077 First published online: April 3, 2012.

http://cercor.oxfordjournals.org/content/early/2012/04/03/cercor.bhs077.short

[193] Marshall R, Lazar R, Mohr JP, Van Heertum R, Mast H. "Semantic" conduction aphasia from a posterior insular cortex infarction. J Neuroimaging. 1996;6:189-191.

[194] Colivicchi F, Bassi A, Santini M, Caltagirone C. Cardia autonomic derangement and arrhythmias in right sided stroke with insular involvement. Stroke 2004;35:2094-2098.

[195] Massetani R, Strata G, Galli R, Gori S, Gneri C, et al., Alteration of Cardiac Function in Patients with Temporal Lobe Epilepsy: Different Roles of EEG-ECG Monitoring and Spectral Analysis of RR Variability. Epilepsia 1997;38(3):363-369.

[196] Locatelli ER, Varghese J, Shuaib A, Potolicchio SJ. Cardiac Asystole and bradycardia as a manifestation of left temporal lobe complex partial seizure. Ann Intern Med 1999;130:581-583. 
[197] Druschky A, Hilz MJ, Hopp P, Platsch G, et al. Interictal cardiac autonomic dysfunction in temporal lobe epilepsy demonstrated by [ $\left.{ }^{123} \mathrm{I}\right]$ metaiodobenzylguanidineSPECT. Brain 2001;124(12):2372-2382.

[198] Ansakorpi H, Korpelainen JT, Huikuri HV, Tolonen U, Myllylä VV, Isojärvi JIT. Heart rate dynamics in refractory and well controlled temporal lobe epilepsy. J Neurol Neurosurg Psychiatry 2002;72:26-30.

[199] Koseoglu E, Kucuk E, Arman F, Ersoy AO. Factors that affect interictal cardiovascular autonomic dysfunction in temporal lobe epilepsy: Role of hippocampal sclerosis. Epilepsy \& Behavior 2009;16(4): 617-621.

[200] Nouri S. Epilepsy and the Autonomic Nervous System. (2010) Full article is availale at the URL: http://emedicine.medscape.com/article/1186872-overview.

[201] Park YS, Lee YH, Shim KW, Lee YL, Kim HD, Lee J-S, Kim D-S. Insular epilepsy surgery under neuronavigation guidance using depth electrode. Childs Nerv Syst ((2009) 25:591-597.

[202] Von Lehe M, Wellmer J, Urbach H, Schramm J, Elger CE and H. Clusmann. Insular lesionectomy for refractory epilepsy: management and outcome. Brain 2009: 132; 10481056.

[203] Meng H, Yudan LV, Cui l, Wang Z, Kin W, et al. Hypothalamus mediates the cardiovascular changes induced by insular epilepsy. Human Health and Biomedical Engineering (HHBE), 2011 International Conference on 19-22 Aug. 2011. Available at the URL:

http://ieeexplore.ieee.org/xpl/login.jsp?tp=\&arnumber=6027962\&url=http\%3A\%2F\%2Fi eeexplore.ieee.org\%2Fxpls\%2Fabs_all.jsp\%3Farnumber\%3D6027962

[204] Enríquez Coronel E, Santos Marcial E, Cabrera Aldana EE. Cerebral cycticercosis vasculitis and optic neuropathy. Case report. Arch. Neurocien (Mex., D.F.) 2004;9(3):

[205] Salcedo-Villanueva G, Rueda-Villa A, Hernández-Ábrego MP. Hemianopsia bitemporal secundaria a hidrocefalia por neurocisticercosis. Archivos de la Sociedad Española de Oftalmología. Full article is free available at the URL:

http://linkinghub.elsevier.com/retrieve/pii/S0365669112003401?via=sd\&cc=y

[206] Kufs T, von basaler F. Cysticerkenmeningitis mit Cysticercus der Hypophhysis und schwerer depressiver Psychose. Z. Ges.Neurol. Psych., 1915;30:286-304.(Cited by Prosser PR)

[207] Dickinson, C. J. Cysticercosis and panhypopituitarism. Proc. R. Soc. Med., 1955; 48:892.

[208] Argenta, G., 1956. Su di un caso di cisticercosis generalizata con sindrome di adenoma ipofisario. Riv. Neurol. (Napoli). 1956;26:197-204.

[209] Briceflo, C. E., Biagi, F., and Martinez, B.,.Cysticercosis. Observaciones sobre 97 casos de autopsia. Prensa Med. Mex., 1961;26:193-197.

[210] Prosser PR, Wilson CB, Forsham PH. Intrasellar cysticercosis presenting as a pituitary tumor: successfully transphenoidal cystectomy with preservation of pituitary function. J Trop Med Hyg.1978;27(5):976-979.

[211] Gómez-Llata RH. Intrasellar cysticercosis. J Neurosurg 1985;63:975-976.

[212] Del Brutto OH, Guevara J, Sotelo J. Intrasellar cisticercosis. J Neurosurg 1988;69:58-60. 
[213] Arriada-Mendicoa N, Celis-López MA, Higuera-Calleja J, Corona-Vázquez T. Imaging features of sellar cysticercosis. Am J Neuroradiol. 2003;24(7):1386-1389.

[214] Rohilla S, Rawal M, Yadac RK, Ahula A, Nanda S, Dhaulakhandi DB. Neurocysticercosis-presenting-as-central-diabetes-insipidus-in-a-boy J Pediat Neurol 2009;7(3):307-310. Full article is available at the URL:

http://www.docstoc.com/docs/44022185/Neurocysticercosis-presenting-as-centraldiabetes-insipidus-in-a-boy

[215] Jin Hwan Cheong, M.D., Jae Min Kim, M.D., Choong Hyun Kim, M.D. Neurocysticercosis Involving the Pituitary Stalk :Case Report and Literature Review. J Korean Neurosurg Soc 2010;48:91-93.

[216] Kelesidis T, Tsiodras S. Hypopituitarism caused by neurocysticercosis. Am J Med Sci. 2011;341(5):414-416.

[217] Del Brutto OH, Sotelo J, Román GC. Neurocysticercosis: A Clinical Handbook. Lisse, the Netherlands: Swets E Zeitlinger;1998.

[218] Del Brutto OH, Sotelo J. Some unusual manifestations of neurocysticercosis. Rev Neurol Neurosurg Psychiatry (Mexico) 1989;29:23-26.

[219] Madrazo I, Sandoval M, González D. Evaluation of the hypothalamic-hypophyseal axis in patients with hypertensive hydrocephalus due to neurocysticercosis. Arch Invest Med (Mex). 1991 Apr-Jun;22(2):113-115.

[220] Lino RS Jr, Reis MA, Teixeira VP. Occurrence of encephalic and cardiac cysticercosis (Cysticercus cellulosae) in necropsy. Rev Saude Publica. 1999;33(5):495-498.

[221] Júnior Lino RS, Reis LC, Reis MA, Gobbi H, Teixeira VP. Hypothalamic neurocysticercosis as a possible cause of obesity. Trans R Soc Trop Med Hyg. 2000 ;94(3):294.

[222] Prajej R, Thananat B, · Pasiri S, Yupin B, Warin 'Ch, Suchinta U, Thanom S. Hypothalamic neurocysticercosis presenting. with polyuria: a first report of an unusual manifestation. Nephrol Dial Transplant. 2006;21:2308-2310.

[223] Garg RK, Malhotra HS. Solitary cysticercus granuloma. Expert Review of Antiinfective Therapy. 2012;10(5):597-612.

[224] Maguire JH, Tierney MR. Case records of the Massachusetts General Hospital. Weekly clinicopathological exercises. Case 8-1993. A 62-year-old Cape Verdean woman with blurred vision, diplopia, a suprasellar mass, and lymphocytic meningitis. N Engl J Med 1993; 328: 566-573.

[225] Amaral L, Maschietto M, Maschietto R, Cury R, Ferreira NF, Mendonça R, Lima SS. Ununsual manifestations of neurocysticercosis in MR imaging: analysis of 172 cases. Arq Neuropsiquiatr. 2003;61(3A):533-541.

[226] Prasad R, Singh R, Joshi B. Lateral sinus thrombosis in neurocysticercosis. Trop Doct. 2005;35(3):182-183.

[227] Sethi PK, Sethi NK, Torgovnick J, Arsura E. Cysticercosis of temporalis muscle: an unusual cause of temporal headaches. A case report. J Headache Pain. 2007;8(5):315-317.

[228] Kumar V, Gulati A, Mehra B. Cysticercosis of the temporalis muscle causing temporal headache in a pregnant woman.Int J Gynaecol Obstet. 2011;114(1):79. 
[229] Sarma DP, Omaha MD. Biopsy of a 1.5-cm cystic lesion on the right cheek of a 28-yearold man. Available at URL: http://www.scribd.com/doc/93186763/CutaneousCysticercosis.

[230] Sidhu R, Nada R, Palta A, Mohan H, Suri S. Maxillofacial cysticercosis: uncommon appearance of a common disease. J Ultrasound Med 2002; 21:199-202.

[231] Pinswasdi P, Charoensiri DJ. Cysticercosis in labial tissue. Case report. Aust Dent J. 1997;42(5):319-321.

[232] Mazhari NJ; Kumar N; Jain S. Cysticercosis of the oral mucosa: aspiration cytologic diagnosis. J Oral Pathol Med 2001; 30:187-189.

[233] de Souza PEA, Barreto DC, da Silva Fonseca LM, Batista de Paula AM, Silva EC, Gomez RS. Cysticercosis of the oral cavity: report of seven cases. Oral Diseases. 2000;6(4): 253-255.

[234] Bhandary S, Sury R, Karki P, Sinha AK: Cysticercosis of Tongue-diagnostic dilemma; Pac Health Dialog. 2004;11(1): 87-88.

[235] Corona S, Apt W. Multiple hydatid cysts and generalized cysticercosis. Rev Med Chil 1989;117:311-314.

[236] Natarajan A, Rameshkumar K, D'Souza RE. Cysticercosis masquerading as a salivary gland neoplasm. Trop Doct 2002;32:120-121.

[237] Chakraborty PP , Bhattacharjee R, Chatterjee K. Parotid Gland Cysticercosis. 2007;55:

[238] Veena G, Shon GM, Usha K, NayarRC. Extracranial cysticercosis of the parotid gland: a case report with a review of the literature. The Journal of Laryngology \& Otology 2008;122(9):1008-1011.

[239] Leelachaikul, Chuahirun S. Cysticercosis of thyroid gland in severe cerebral cysticercosis: report of a case. J Med Assoc Thai 1977;60:405-10.

[240] Scholtz L, Mentis H. Pulmonary cysticercosis. SAMT1987; 72( 1): 573.

[241] Smiti S, Sripathi H, Naik L. Cricothyroid muscle cysticercosis. Muscoloskeletal 2003: 13(2):157-158.

[242] Sobnach S, Khosa SA, Pather S, Longhurst S, Kahn D, Raubenheimer PJ. First case report of pharyngeal cysticercosis. Trans R Soc Trop Med Hyg. 2009;103(2):206-208.

[243] Sodhi PK, Ratan SK. Submandibular lymph node enlargement due to cysticercosis infestation. Scandinavian journal of infectious diseases. 2004;36: 227-229.

[244] Geeta V, Devi P, Sirisha A, Devi R, Bai J, Kumar S. Unusual location of Cysticercosis lesion presentation. JEMDS 2012;42. Article is fully available at the URL: http://www.jemds.com/latest-articles.php?at_id=42 (Last checked on August 27, 2012)

[245] Vikas Sinha V, Raizada RM, Jain SKT, Chaturvedi VN. Cysticercosis of Submandibular Duct. Indian Journal of Otolaryngology and Head \& Neck Surgery. 1999;51(4):51-52.

[246] Sharma R, Gautam P, Kumar S, Elhence P, Bansal R, et al. Isolated Cysticercosis Cellulosae of Sternocleidomastoid Muscle: A Case Report with Review of Literature. Indian Journal of Otolaryngology and Head \& Neck Surgery 2011;24:127-130.

[247] Thomas MB, Thomas KM, Awotedu AA, Blanco-Blanco E, Anwary M. Cardiocysticercosis.S Afr Med J 2007;97(7):504-505. 
[248] Eberly MD, Soh EK, Bannister SP, Taraf-Motamen H, Scott JS: Isolated Cardiac Cysticercosis in an adolescent; Pediatr Infect Dis J. 2008; 27(4); 369-71.

[249] Jain BK, Sankhe SS, Agrawal MD, Naphade PS. Disseminated cysticercosis with pulmonary and cardiac involvement. Indian J Radiol Imaging 2010;20:310-313.

[250] Mamere AE, Muglia VF, Simao GN, Belucci AD, Carlos dos Santos A, Trad CS, et al. Disseminated cysticercosis with pulmonary involvement. J Thorac Imaging 2004;19:109-111.

[251] Bhigjee AI. Disseminated cysticercosis. J Neurol Neurosurg Psychiatry 1999;66(4):545

[252] Banu A, Veena N. A rare case of disseminated cysticercosis: Case report and literature review. Case Report. 2011;29(2):180-183.

[253] Kumar A, Goenka AH, Choudhary A, Kumar Sahu JK, Gulati S.Disseminated cysticercosis in a child: whole-body MR diagnosis with the use of parallel imaging. Pediatric Radiology 2110;45:223-227.

[254] Smiti S, Sripathi H, Naik L. Pectoralis Major muscle cysticercosis. MUSCULOSKELETAL 2003;13(2):157-158.

[255] Wadia N, Deasi S, Bhat M. Disseminated cysticercosis; new observations, including CT scan finding and experience with treatment by praziquantel. Brain 1988; 111: 597-614.

[256] Saxena H, Samuel KC, Singh B. Cysticercosis of the heart. Indian Heart J 1972;24: 313315.

[257] Niakara A, Cisse R, Traore A, et al. Myocardial localization of a disseminated cisticercosis.

[258] Cutrone JA, Georgiou D, Gil-Gomez C, Burndage BH. Myocardial cysticercosis detected by ultrafast CT. Chest 1995; 108:1752-1754.

[259] Rahalkar MD, Shetty DD, Kelkar AB, Kelkar AA, Kinare AS, Ambardekar ST. The many faces of cysticercosis. Clin Radiol 2000; 55 (9): 668-674.

[260] Ibarra-Perez C, Fernandez-Diez J, Rodriguez-Trujillo F. Myocardial cysticercosis, report of two cases with coexisting heart disease. South Med J 1972; 65: 484-486.

[261] Deshpande VL, Patil SD. Silent myocardial cysticercosis. Indian Heart J 1976; 28(1): 5860.

[262] Belagavi CS, Goravalingappa JP. Cysticercosis of the heart. A case report. Indian Heart J 1978;30: 118-119.)

[263] Kirchhoff LV, Weiss LM, Wittner M, Tanowitz HB. Parasitic diseases of the heart. Front Biosci. 2004;9:706-723.

[264] Fan PC, Chung WC, Guo JX, Ma YX, Xu ZJ. Experimental studies on physiological and morphological aspects of Cysticercus cellulosae in pigs. J Microbiol Immunol Infect. 2001;34(4):252-258.

[265] Franco-Paredes C, Rouphael N, Méndez J, Folch E, Rodríguez-Morales AJ, Santos JI, Hurst JW. Cardiac manifestations of parasitic infections part 3: pericardial and miscellaneous cardiopulmonary manifestations. Clin Cardiol. 2007;30(6):277-280.

[266] Franco-Paredes C, Rouphael N, Méndez J, Folch E, Rodríguez-Morales AJ, Santos JI, Hurst JW. Cardiac manifestations of parasitic infections part 1: overview and immunopathogenesis. Clin Cardiol. 2007;30(4):195-199. 
[267] Hidron A, Vogenthaler N, Santos-Preciado JI, Rodriguez-Morales AJ, Franco-Paredes C, Rassi A Jr. Cardiac involvement with parasitic infections. Clin Microbiol Rev. 2010 ;23(2):324-349.

[268] Salaria M, Parmar V, Kochar S, Mehta S. Eosinophilia, Pleural Effusion and Cysticercosis - Unknown Association? Indian Pediatrics 2001; 38: 671-674.

[269] Mayo F, Baier H. Cysticercotic cyst involving the pleura. An unusual case of an abnormal chest roentgenogram. Arch Intern Med. 1979;139(1):115-116. http://www.scielo.br/scielo.php?pid=S0036-46651991000200007\&script=sci_abstract

[270] Yaqoob N, Haq EU,Thomali K, Kamran A, Zaharani A. Cysticercosis of Soft Tissue (BREAST). Journal of Pakistan Medical Association.2009;59(2):108-110.

[271] Agnihotri S, Talwar OP, Pudasaini S, Baral R. Cysticercosis of breast - a case report. Pol J Pathol 2006; 57:53-54.

[272] Lucarelli AP, Martins MM, Marques de Oliveira V, Rinaldi JF, Roveda Jr D., Longo Galvão MA, et al. Cysticercosis of the Breast, a Rare Imaging Finding. Am. J. Trop. Med. Hyg.,2008;79(6):864-865.

[273] Chew NK, TAN CT, GOH KJ, Kamarulzaman A, Paul G, Ramli N, Anuar K. The first case of neurocysticercosis diagnosed ante-mortem in Malaysia. Neurol J Southeast Asia 2001;7:135-138.

[274] Mani NB, Kalra N, Jain M, Sidhu R. Sonographic diagnosis of a solitary intramuscular cysticercal cyst. J Clin Ultrasound 2001; 29:472-475.

[275] Inamadar AC, Yelikar BR. Cysticercosis cellulose cutis. Indian J Dermatol Venereol Leprol. 2001 Jul-Aug;67(4):198-189.

[276] Abdelwahab IF, Klein MJ, Hermann G, Abdul-Quader M. Solitary cysticercosis of the biceps brachii in a vegetarian: a rare and unusual pseudotumor. Skeletal Radiol 2003; 32:424-428.

[277] Yamasaki H, Nagase T, Kiyoshige Y, Suzuki M, Nakaya K, Itoh Y, et al. A case of intramuscular cysticercosis diagnosed definitively by mitochondrial DNA analysis of extremely calcified cysts. Parasitol Int 2006; 55:127-30.

[278] Nagaray C, Singh S, Joshi A, Trikha V: Cysticercosis of biceps brachii: a rare cause of Posterior Interosseous nerve syndrome; Joint Bone Spine. 2008;75(2):219-221.

[279] Jankharia B, Chavan G, Krishnan, Jankharia B: MRI and Ultrasound in solitary muscular and soft tissue cysticercosis; Skeletal Radiol.2005; 34: 722-726.

[280] Mani NBS , Kalra N et al Sonographic diagnosis of solitary intramuscular Cysticercal cyst. J clin ultrasound. 2001;29:472-475.

[281] Tripathy SK, Sen RK, Sudes P, Dhatt S. Solitary cysticercosis of deltoid muscle in a child: The diagnostic dilemma and case report. J of Orthopaedics 2009;6:e11.

[282] Asrani A, Morani A. Primary sonographic diagnosis of disseminated muscular cysticercosis. J Ultrasound Med 2004;23:1245-1248.

[283] Jhankaria BG, Chavhan GB, Krishnan P, Jhankaria B. MRI and ultrasound in solitary muscular and soft tissue cysticercosis. Skeletal Radiol 2005;34:722-726.

[284] Sirikulchayanonta V, Jaovisidha S. Correlation of Magnetic Resonance Imaging and Histopathology. J Med Assoc Thai 2007;90(6):1248-1252. 
[285] Smiti S, Sripathi H, Naik L.Cysticercosis in the right thigh. MUSCULOSKELETAL 2003;13(2):157-158.

[286] Sirikulchayanonta V, Sirikulchayanonta Ch, Leopairat J.A Descriptive study of 36 cases of solitary soft tissue cysticercosis at Ramathibodi Hospital. Southeast Asian J Trop Med Public Health. 2007;38(3): 407.

[287] Yamasaki H, Nagase T, Kiyoshige Y, Suzuki M, Nakaya K, Itoh Y, et al. A case of intramuscular cysticercosis diagnosed definitively by mitochondrial DNA analysis of extremely calcified cysts. Parasitol Int. 2006;55:127-130.

[288] Inamadar AC, BR Yelikar BR. Cysticercosis cellulose cutis. Indian J Dermatol Venereol Leprol 2001;67(4):198-199.

[289] Ogilvie CM, Kasten P, Rovinsky D, Workman KL, Johnston JO. Cysticercosis of the triceps: an unusual pseudotumor. Clin Orthop 2001; 382:217-221.

[290] Akhtar MN, Sharat Agarwal S.Disseminated cysticercosis incidentally diagnosed in a patient of low backache: a case report and concise review of literature. Asian Pac J Trop Med Jul 2012.

[291] Foyaca-Sibat H, Ibanez-Valdes LdeF, Mashiyi MK. Disseminated cysticercosis. One day treatment in a case. Electron J Biomed 2004;3:39-43. http://www.biomed.edu/2004/ n1/foyaca.html

[292] Park SY, Min HK, Jung HK, Kwan YS. Disseminated cysticercosis. Journal of Korean Neurosurgical Society. 2011;49(3):190-193.

[293] Sirikulchayanonta V, Jaovisidha S: An intramuscular cysticercosis, a case report with correlation of magnetic resonance imaging and histology; J Med Assoc Thai. 2007;90(6):1248-1252.

[294] Jacob JC, Mathew NT, 1968. Pseudohypertrophic myopathy in cysticercosis. Neurology 18: 767-771.

[295] Gill M, Dua S, Gill P, Gupta V, Gupta S, Sen R . Cytomorphological spectrum of subcutaneous and intramuscular cysticercosis: A study of 22 cases. J Cytol 2010; 27(4):123-126.

[296] Sawhney BB, Chopra JS, Banerji AK, Wahi PL, 1976. Pseudohypertrophic myopathy in cysticercosis. Neurology 1976;26:270-272.

[297] Armbrust-Figueiredo J, Speciali JG, Lison MP, 1970. Forma miopatica da cisticercose. Arq Neuropsiquiatr 28: 385-390.

[298] Naik D, Srinath MG, Kumar A.Soft tissue cysticercosis - Ultrasonographic spectrum of the disease. Indian Journal of Radiology and Imaging. 2011;21(1):60-62.

[299] GA Anderson, SM Chandi: Cysticercosis of the Flexordigitorum profundus muscle producing flexion deformity of the fingers; J of Hand Surgery (British \& European Volume), 1993; Vol.18, No.3; 360-36.

[300] Sharat Agarwal, Paragjyoti Gogoi: An unusual case of Cysticercosis of the tendon sheath of Tendoachilles - A case report; Electronic Physician. 2010; 2: 45-48.

[301] Ray M, Kothur K. Entrapment ulnar neuropathy caused by cysticercosis. Journal of Pediatric Neurology. 2006;4(3):203-206. 
[302] Kurrein F, Vickers AA. Cysticercosis of the spine. Ann Trop Med Parasitol. 1977 ;71(2):213-217.

[303] Kumar P,AnsariJA, Dwivedi S, Sinha AK. Peripheral Joint Pain, Hypertension, Multiple Skeletal and CNS Calcific Lesions. JIACM 2002; 3(2):148-152.

[304] Banu A, Veena N A rare case of disseminated cysticercosis: case report and literature review. Indian J Med Microbiol 2011 Apr-Jun; 29(2):180-1833.

[305] Mani NB, Kalra N, Jain M, Sidhu R. Sonographic diagnosis of a solitary intramuscular cysticercal cyst. J Clin Ultrasound 2001; 29:472-475.

[306] Bangal V , Kwatra A, Garg S. Rare case of cysticercosis of rectus abdominis muscle presenting as pelvi abdominal lump during puerperium. Pravara Med Rev 2010; 5(2):2124.

[307] Khan RA, Wahab S, Chana RS A. Rare Cause of Solitary Abdominal Wall Lesion. Iran J Pediatr. 2008;18(3):291-292.

[308] Mittal A, Sharma NS 2008 Sep : Psoas muscle cysticercosis presenting as Acute Appendicitis; J Clin Ultrasound. 2008 Sep; 36(7): 430-431.

[309] Mohan H, Bal A, Aulakh R. Multiple cysticerci as an unusual cause of mesenteric lymph node enlargement: a case report. Journal of Medical Case Reports 2008,2:196.

[310] Vianna LG, Macedo V, Costa JM. Cutaneous, muscular and visceral cysticercosis - a rare disease? Rev. Inst. Med. trop. S. Paulo 1991;33(2):129-136.

[311] G Everett, de Gruchy PH. Hepatic cysticercosis Veterinary Record 1982;111:24 565.

[312] Fultz PJ, Penwarden B, Laczin J.Hepatic cysticercosis. Report of an unusual case. J Clin Gastroenterol. 1995;20(2):160-163.

[313] Figurnov VA, Churin AN, Lenshin AV, Grigorenko AA, Churina SA, Figurnova EV, Soldatkin PK. .A case of isolated hepatic cysticercosis in a nine-year-old girl. Med Parazitol (Mosk). 2002 ;(1):56-57.

[314] Vishwanath S, Charudutt S, Kavitha S, Abdul R, Ashwin P, Rao SN. (2011) A rare case of hepatic cysticercosis. Asian Pacific Journal of Tropical Biomedicine 2011;1(1)139-140.

[315] Bal MS, Suri A, Kumar R, Vijay M. Disseminated cysticercosis in a post mortem case. J Punjab Acad Forensic Med Toxicol 2012;12(1):40.

[316] Jain BK, Sankhe SS, Agrawal MD, Naphade PS.Disseminated cysticercosis with pulmonary and cardiac involvement. Indian J Radiol Imaging. 2010; 20(4):310-313.

[317] Jakhere SG, Chemburkar VC, Yeragi BS, Bharambay HVImaging findings of disseminated cysticercosis with unusual involvement of spleen and pancreas. J Glob Infect Dis 2011;3(3):306-308.

[318] Bal MS, Suri A, Kumar R, Vijay M. Disseminated cysticercosis in a post mortem case. J Punjab Acad Forensic Med Toxicol 2012;12(1):40.

[319] Norman RJ. Tetraphyllidean cysticerci in the peritoneal cavity of the common dolphin. J Wildl Dis. 1997;33(4):891-895.

[320] Chung WC, Lin CY, Fan PC. Ectopic locations of Taenia saginata asiatica cysticerci in the abdominal cavity of domestic pig and monkey. J Parasitol. 1996;82(6):1032-1034.

[321] Dyer NW, Greve JH. Severe Cysticercus Longicollis Cysticercosis in a Black Lemur (Eulemur Macaco Macaco. J VET Diagn Invest 1998;10:362. 
[322] Fraga CM, Costa TL, Bezerra JC, de Souza Lino Junior R, Vinaud MC.Fatty acids oxidation and alternative energy sources detected in Taenia crassiceps cysticerci after host treatment with antihelminthic drugs. Exp Parasitol. 2012;131(1):111-115.

[323] Stringer JL, Marks LM, White AC Jr, Robinson P. Epileptogenic activity of granulomas associated with murine cysticercosis. Exp Neurol. 2003;183(2):532-536.

[324] Vincent JM, Morrison ID, Armstrong P, Reznek RH.The size of normal adrenal glands on computed tomography. Clin Radiol. 1994;49(7):453-455.

[325] Rajatanavin R, Dheandhanoo D, Siridej N, Somburanasin R. Cerebral cysticercosis simulating pheochromocytoma: a case report. J Med Assoc Thai. 1981;64(7):351-355.

[326] Liu Y, Wang L. Telemedicine in border area of China. Telemed J. 1998;4(1):39-41.

[327] Kelesidis T, Tsiodras S. Hypopituitarism caused by neurocysticercosis. Am J Med Sci. 2011;341(5):414-416. 